NASA Technical Memorandum 106287

$1 N-37$

AIAA-93-2396

185024

$24 \rho$

\title{
A Soft-Start Circuit for Arcjet Ignition
}
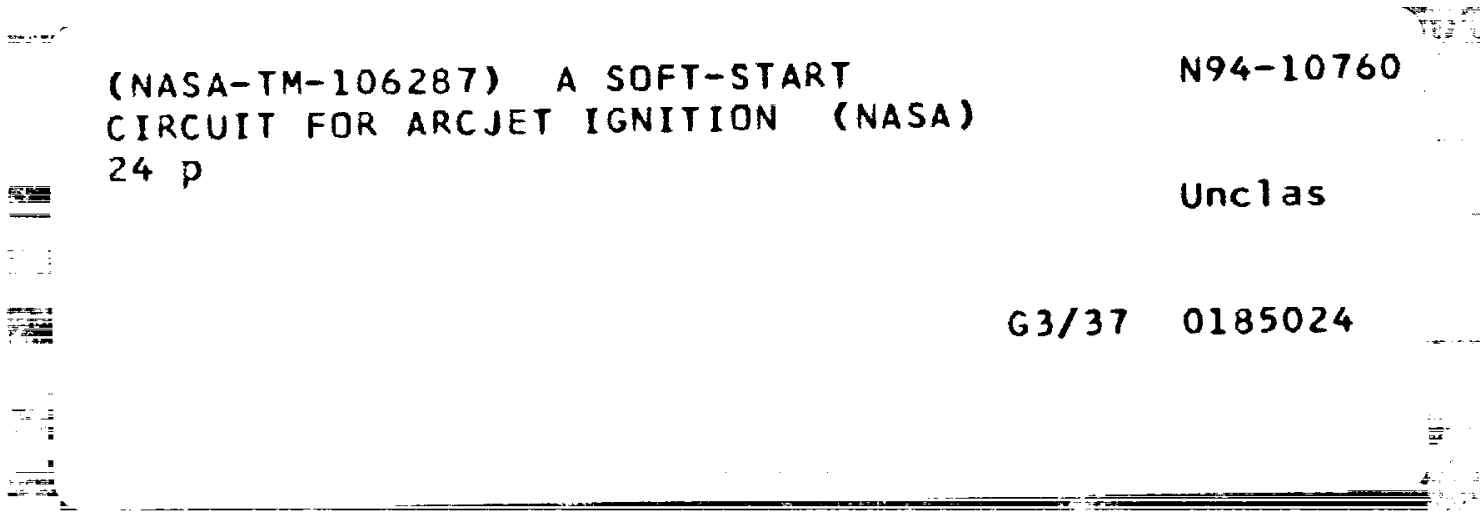

John A. Hamley and John M. Sankovic

Lewis Research Center

Cleveland, Ohio

Prepared for the

29th AIAA Joint Propulsion Conference and Exhibit cosponsored by the AIAA, SAE, ASME and ASEE Monterey, California, June 28-30, 1993 


\title{
A SOFT-START CIRCUIT FOR ARCJET IGNITION -
}

\author{
John A. Hamley* and John M. Sankovic** \\ National Aeronautics and Space Administration \\ Lewis Research Center \\ Cleveland, Ohio 44135
}

\begin{abstract}
The reduced propellant flow rates associated with high performance arcjets have placed new emphasis on electrode erosion, especially at startup. A soft-start current profile was defined which limited current overshoot during the initial 30 to $50 \mathrm{~ms}$ of operation, and maintained significantly lower than the nominal arc current for the first eight seconds of operation. A 2-5 kW arcjet PPU was modified to provide this current profile, and a 500 cycle test using simulated fully decomposed hydrazine was conducted to determine the electrode erosion during startup. Electrode geometry and mass flow rates were selected based on requirements for a 600 second specific impulse mission average arcjet system. The flow rate was varied throughout the test to simulate the blow down of a flight propellant system. Electrode damage was negligible at flow rates above $33 \mathrm{mg} / \mathrm{s}$, and minor chamfering of the constrictor occurred at flow rates of 33 to $30 \mathrm{mg} / \mathrm{s}$, corresponding to flow rates expected in the last $40 \%$ of the mission. Constrictor diameter remained unchanged and the thruster remained operable at the completion of the test. The soft-start current profile significantly reduced electrode damage when compared to state of the art starting techniques.
\end{abstract}

\section{INTRODUCTION}

Arcjet research in the 1960's centered on high power hydrogen arcjets for orbit transfer applications, with some development work directed toward a kilowatt class device for stationkeeping and attitude control. Cancellation of the SNAP-8 program halted research on arcjets until the mid 1980's. A summary of the data compiled during this time frame was published by Wallner and Czika. ${ }^{1}$ Arcjet ignition was accomplished using various techniques including electrode contact, Paschen breakdown at reduced flow rates, and high voltage DC. 2-3 These techniques, though successful at initiating the arc discharge, caused significant and unacceptable electrode damage.

In the mid 1980's research focused on hydrazine arcjets at the 1-2 kW power level for stationkeeping applications. A pulse ignition technique was developed by Sarmiento and Gruber ${ }^{4}$ which was incorporated in a prototype power processing unit (PPU). ${ }^{5}$ This technique caused minimal damage to the thruster electrodes at higher flow rates then of interest during the ignition and transition to steady state. ${ }^{6}$ This prototype arcjet/power processor system evolved into a flight system which was baselined for series of geosynchronous communications satellites. ${ }^{7}$

The areas of arcjet propulsion currently emphasized at NASA Lewis are sub-kilowatt power levels for power limited spacecraft, next generation high specific impulse engines at $2-5 \mathrm{~kW}$ for stationkeeping and orbit change, and high power arcjets for orbit transfer applications. Each of these areas present challenges for power control during the ignition of the arc and the transition to steady state operation. In the case of sub-kilowatt class thrusters, small electrode geometries and low mass flow rates increase the probability of electrode damage during the ignition phase when present starting techniques are used. The high specific impulse thrusters also operate at flow rates lower than those presently employed at the 2 $\mathrm{kW}$ power level. In addition to similar concerns for high power thrusters, previous ignition techniques resulted in step changes in bus power demand from zero to full load in a few microseconds. This transient may result in other problems including interactions with distribution networks.

These issues can be mitigated by a so-called soft-start ignition approach. A soft-start circuit was developed which limited the initial arc current to a preset level below the nominal operating current and limited the initial overshoot to as little as $25 \%$ of the initial value. The arc current was held at this lower level for a preset time and was then ramped up to the nominal operating value. The overshoot, initial, and nominal arc currents were adjustable, as was the time interval at the initial arc current. This soft-start circuit was installed in a NASA Lewis $2-5 \mathrm{~kW}$ PPU and used in conjunction with a laboratory model $2 \mathrm{~kW}$ arcjet in a test which included 500 starts and flow rates for a $600 \mathrm{~s}$ nominal mission average specific impulse. This paper presents the description of the soft-start current profile and the

* Electrical Engineer, On-Board Propulsion Branch

** Aerospace Engineer, On-Board Propulsion Branch, Member AIAA

Copyright $\odot 1993$ by the American Institute of Aeronautics and Astronautics, Inc. No copyright is asserted in the United

States under Title 17, U.S. Code. The U.S. Govemment has a royalty-free license to exercise all rights under the copyright

claimed herein for Governmental purposes. All other rights reserved by the copyright owner. 
results of the 500 start test.

\section{BACKGROUND}

Several power processors for arcjet applications encompassing a power range from 0.4 to $10 \mathrm{~kW}$ have been developed.5,8-11 All of these designs have utilized current mode pulse width modulation (PWM) for regulation of the output current. A simplified schematic diagram of a push-pull topology PPU is presented in Figure 1. Current mode PWM in this application utilizes the relation that the primary current in the transformer and the load current are proportional by the inverse of the turns ratio of the transformer. The primary current $i_{p}$, and load current $i_{L}$ are defined as shown in Figure 1.

A simplified block diagram of the PWM controller used in the PPUs designed at NASA LeRC is shown in Figure 2a. The switching frequency of the PPU is controlled by the oscillator, which operates at twice the desired switching frequency. Switch $\mathrm{S} 1$, in Figure 1, is turned on by the first rising edge of the oscillator output and is turned off by the PWM controls before the next rising edge of the oscillator output which then turns on S2. In this fashion, an altemating current of one-half the oscillator frequency is set up in the transformer primary. The "on" time of the power switches is varied from zero to one full oscillator clock period, depending on the PWM control output. This corresponds to a 0 to $100 \%$ output condition. Output current regulation is accomplished by the integration of the difference of the load current and the current reference, as shown in Figure 2a. The output of the integrator is then compared to the primary current. When the primary current level crosses the error signal, the power switch is turned off. In this fashion, the peak primary current is maintained at a fixed value, thus regulating the output current. If the output current is below the desired reference, the integrator output increases, thus increasing the primary current. Conversely, if the output current is above the reference value, the integrator output decreases. In the steady state case where the output current is exactly equal to the reference, the integrator output is constant. As a safety measure, a maximum primary current limit reference is provided which turns off the transistor power switches when the primary current reaches this preset value. This is illustrated graphically in Figure $2 \mathrm{~b}$, which shows the switch "on" times in relation to the oscillator rising edge, the PWM comparator, and the current limit comparator.

A typical current profile of an arcjet start is shown in
Figure 3. When the PPU and its controls are powered on, the arcjet is in a non-conducting state. As a result, the integrator detects a large error between the current reference and the actual arc current, which is zero prior to ignition. Saturation of the integrator occurs, causing the PWM controller to set the PPU to the full output and the PPU develops its full open circuit voltage. The error signal in this case will exceed the current limit reference. A high voltage pulse train is also applied to the output to break down the propellant gas. If the pulse is of sufficient amplitude and energy, the arcjet will break down into a low voltage discharge or low mode. The low voltage discharge is characterized by a spot attachment between the cathode and convergent section of the anode as shown in Figure 4. These low mode discharges are unavoidable, and are a normal consequence of arcjet ignition. Extended operation in low mode however, can result in significant electrode damage as illustrated by the photograph of the convergent side of an arcjet anode in Figure 5.12 The anode in the figure has been subjected to approximately 25 starts, and several arc tracks are quite clear from the point of initial attachment to the constrictor. This rate of erosion is unacceptable for any application which requires cyclic operation. Typical voltages for this type of discharge range from $30-60 \mathrm{~V}$, which are generally less than $40 \%$ of the typical operating voltage of the arcjet and 20 to $40 \%$ of the PPU open circuit voltage. This leaves only the output of the inductance of the PPU and the primary current limiter to control the arc current until the enror integrator recovers. Unfortunately, the current limit is set in practice to $30 \%$ of the maximum output current of the PPU, resulting in a 30 $\%$ or greater overshoot in the arc current. This has not been a problem in the past with $1 \mathrm{~kW}$ class arcjets operating at specific impulse levels below $500 \mathrm{s.}^{6}$ However, significant damage can result from the low flow rates used in high performance arcjets without proper control of current during the normal low mode interval at start up.

\section{APPROACH}

An apparent solution to the problem is a bi-level current reference which would start the arcjet at a low current and ramp the current up to the final operational level after a fixed time period. The shortcoming of this scheme can be illustrated using the arcjet start in Figure 3. The PPU will always start the arcjet at the current limit value for the first $5-10 \mathrm{~ms}$ of operation. The ramp down rate to the final value is also constant due to the time response of the error integrator. Therefore, the arcjet will still operate at high currents for the critical first milliseconds in low mode. 
The approach selected for this work combines a bi-level arc current reference, with a bi-level current limit reference. Both references are set at low values during the first few seconds of arcjet operation to limit the arc current during low mode and the transition to the diffuse, steady state anode attachment. This approach is illustrated in Figure 6. Prior to the application of the high voltage pulses, the arc current reference and the current limit are set to user-selected values. The current limit must be set to a value that is at least 20 to $25 \%$ greater than the desired start current to force the error integrator to ramp down from saturation rapidly and ensure stable operation. After the arcjet has run for a predetermined time, the current limit is rapidly raised to its final value and the arc current reference is slowly ramped up to the final value. This approach allows for the adjustment of the three current levels, the time the arcjet is operated at the low current setpoint, and the ramp rate to the final arc current.

\section{APPARATUS}

A modular $1 \mathrm{~kW}$ arcjet with a tapered seal anode was used for the cyclic test and the construction details were described in reference 13. Prior to installation of the anode, the tapered seal was lapped into the anode housing to provide a gas-tight seal. A 2:1 stoichiometric mixture of hydrogen and nitrogen gas was used as propellant for the tests to simulate fully decomposed hydrazine.

The electrode geometry selected for this test was chosen based on the performance requirements of 600 seconds at $2 \mathrm{~kW}$. The cathodes used were conically-tipped, 31.7 $\mathrm{mm}$ diameter, $2 \% \mathrm{ThO}_{2} / \mathrm{W}$ rods with a half angle of 30 degrees. The anode was also $2 \% \mathrm{ThO}_{2} / \mathrm{W}$ with a converging half angle of 30 degrees, to match the cathode tip, and a 20 degree half angle in the diverging section. The constrictor diameter was $0.46 \mathrm{~mm}$. The arc gap was set by inserting the cathode until contact with the anode was made, and then withdrawing the cathode $0.64 \mathrm{~mm}$.

The arcjet was installed in a $0.64 \mathrm{~m}$ diameter belljar evacuated by a single mechanical pump with a pumping speed of $21,000 \mathrm{l} / \mathrm{m}$. The belljar pressure was maintained at $100 \mathrm{~Pa}$ at the maximum thruster flow rate. The facility was equipped with a programmable controller capable of automated cyclic testing, maintaining constant flow rates with thermalconductivity-type mass flow controllers, and cycling the power processor at pre-programmed intervals. The PPU used in these tests was a $2-5 \mathrm{~kW}$ unit, described in reference 8 , which was modified to include the soft-start feature.

\section{EXPERIMENTAL PROCEDURE}

A 500 start cyclic test was conducted to determine the effectiveness of this starting technique with flow rates that corresponded to a nominal mission average specific impulse of 600 seconds at $2 \mathrm{~kW} .14$ The test was divided into five segments of one hundred starts, and the flow rates were selected for each segment to simulate the flow profile of a flight propellant system in a step-wise fashion. These flow rates are listed in Table I. The start current profile of Figure 6 was used with the start current limit set to $10 \mathrm{~A}$, and the start current setpoint at $8 \mathrm{~A}$. This corresponded to an overshoot of $2 \mathrm{~A}$ or $25 \%$. The final current was set to $14 \mathrm{~A}$, and the ramp time was $500 \mathrm{~ms}$ as shown in Figure 6. The high current setpoint was selected to protect the anode housing from thermal damage and resulted in a steady state power that was lower than required for 600 second operation. Since the focus of the experiment was to assess damage incurred during low mode operation, the steady state power was reduced to mitigate other damage not related to startup.

A scanning electron micrograph of the anode was made before the test as a reference to assess post-test anode damage. The arcjet electrodes were then weighed after the anode was lapped to fit in the anode housing and the arc gap set as described in the previous section. The arcjet was then installed in the facility. Each cycle consisted of five minutes of steady state operation, followed by a ten minute cool down period, giving 4 cycles per hour. Flow rate, arc current, arc voltage, and propellant feed pressure were continuously monitored with a strip chart recorder.

After each 100 cycle segment, the arcjet was disassembled and the electrodes were inspected with an optical microscope. The electrodes were then weighed to determine the extent of material loss, if any. The anode was then re-lapped to ensure that a proper seal existed with the housing, but the internal surfaces were not modified in any way. The anode was then weighed, along with a new cathode, and the arcjet was assembled and the electrode gap reset. A new cathode was installed for each segment of the test to determine the extent of the cathode wear at each flow rate. 


\section{RESULTS AND DISCUSSION}

\section{Current Profile}

An oscillograph of the start current profile used in the tests appears in Figure 7. The peak arc current at startup was $10 \mathrm{~A}$, with a rapid ramp down to the start level of 8 A. The noise in the $8 \mathrm{~A}$ section of the trace is an artifact of the digital storage oscilloscope, due to aliasing of the high frequency PPU ripple current. The ramp up from 8 to 14 A takes place within $500 \mathrm{~ms}$. The first $180 \mathrm{~ms}$ of Figure 7 is shown in greater detail in Figure 8. The total time the PPU was in the current limit mode at 10 A output was approximately $30 \mathrm{~ms}$. The initial $5 \mathrm{~ms}$ of the start up, shown in Figure 9, displayed no significant overshoot.

The pre-test micrographs of the anode are shown in Figures $10 \mathrm{a}$ and $10 \mathrm{~b}$. The converging section in Figure 10a was smooth, except for machining marks, and the constrictor was circular and undistorted. The $100 \mathrm{X}$ photograph showed no evidence of cracking, and the edges of the constrictor were sharp and well defined. The pre and post-test masses of the electrodes are listed in Table II. The reduction of anode mass from the end of one test to the beginning of another was from lapping the external surfaces of the anode to ensure a gas tight seal with the anode housing.

\section{Cycles 1-100}

Cathode " $\mathrm{A}$ " was used in the first 100 cycles and the mass flow rate for this test segment was $45 \mathrm{mg} / \mathrm{s}$. Observation of the first starts revealed no evidence of the ejection of molten electrode material, and 100 cycles were completed without difficulty. A strip chart record of the first start, showing the arc current, voltage and propellant feed pressure is shown in Figure 11. The arc current profile is identical to that of Figure 7, but shown on a longer time scale. The initial arc current at breakdown is $10 \mathrm{~A}$, and rapidly ramps down to $8 \mathrm{~A}$ for eight seconds, and then ramps up to the operating value of $14 \mathrm{~A}$. The arc voltage trace shows stable operation of the arcjet during the low current segment, with a monotonic increase in the voltage as the feed pressure increased due to the electrode heating. As the current was ramped to $14 \mathrm{~A}$, the arc voltage decreased, as expected from the negative slope impedance characteristics associated with arcjets.

Post-test micrographs of the anode appear in Figures $12 \mathrm{a}$ and $12 \mathrm{~b}$. The micrograph of the convergent section showed some arc texturing near the constrictor opening, but in general, the anode was in excellent condition. The arc texturing was evenly distributed and there were no distinctly damaged regions, and the constrictor was circular with no apparent distortions or erosion. The diameter of this textured region was approximately 1.6 $\mathrm{mm}$, and the total mass loss to the anode was less than $1 \mathrm{mg}$. The divergent section was unchanged, as seen in Figure 12b. Pre and post-test micrographs of the cathode appear in Figure 13a and 13b. The cathode was also in good condition, with some mass loss from the tip, which was expected. However, the mass loss was less than $1 \mathrm{mg}$. A very small region of texturing was observed near the very tip of the cathode, which indicated that the arc attachment during startup was confined to a region near the tip.

\section{Cycles $101-200$}

Cathode " $B$ " was installed in the thruster, and the mass flow rate reduced to $41 \mathrm{mg} / \mathrm{s}$. Observations of the first few cycles again had no evidence of molten electrode material ejection. A strip chart recording for cycle 101 , shown in Figure 14, indicated stable operation of the thruster. The thruster operating voltage and pressures were lower due to the reduction in the mass flow rate.

Post test micrographs of the anode, shown in Figure $15 \mathrm{a}$ and $15 \mathrm{~b}$, indicated an increase in the diameter of the arc textured region to $1.8 \mathrm{~mm}$. A slight irregularity also was evident on the constrictor, and some material was ejected onto the diverging section, shown in Figure 15b. Again, this damage was considered slight. The total mass of the anode remained essentially constant, and the cathode lost on the order of one-half milligram of material. The pre and post-test micrographs of cathode "B" are shown in Figure 16a and 16b. Again, mass loss was concentrated at the cathode tip, but interestingly, the textured region extends further toward the rear of the cathode, indicating arc attachment further back from the tip during startup.

\section{Cycles 201-300}

Cathode " $\mathrm{C}$ " was installed in the thruster, and the mass flow rate set to $37 \mathrm{mg} / \mathrm{s}$. The initial starts were observed to be uneventful. The strip chart record for cycle 201, shown in Figure 17, indicated that the thruster operation was again stable.

Post test micrographs of the anode, shown in Figures $18 \mathrm{a}$ and $18 \mathrm{~b}$ again revealed an increase in the diameter of the textured region. In this case, the textured region was $2.0 \mathrm{~mm}$ in diameter. The upper left quadrant of the converging section showed more wear, and a slight 
deformation of the constrictor region was evident. The diameter of the constrictor was unchanged, but there was a definite chamfering of the upstream section for $120^{\circ}$ of the circumference. The micrograph of the divergent section in Figure 18b clearly shows deposition of material, that likely came from the convergent section. The mass of the anode was essentially unchanged. The pre- and post-test micrographs of cathode " $\mathrm{C}$ ", shown in Figure 19a and 19b, again show loss of mass from the cathode tip. The textured region near the tip again extended further back on the conical section of the cathode than in the previous tests.

\section{Cycles $301-400$}

Cathode " $D$ " was installed in the thruster and the mass flow rate reduced to $33 \mathrm{mg} / \mathrm{s}$. Minor ejection of molten material was noted during the first start, and the strip chart record of Figure $\mathbf{2 0}$ shows some instability in the voltage trace during the initial eight second low current interval and also in the high current segment, but to a lesser degree. Material ejection was observed to correspond with rapid, downward excursions in the arc voltage, indicating brief intervals of attachment near the constrictor in the converging section. The arc current remained constant during the excursions into low mode due to the rapid transient response of the PPU.

The arc textured section of the converging section increased in diameter to $2.2 \mathrm{~mm}$, as shown in Figure 21 a. The chamfering of the constrictor also worsened and extends for approximately $240^{\circ}$ of the circular orifice. The elliptical appearance of the constrictor was an artifact of the photographic process, as the anode was unfortunately askew in the sample holder. A micrograph of the diverging section, shown in Figure 21b shows additional deposition of material on the surface. The region of deposition corresponded exactly to the arc chamfered region of the converging section. Again, less than $1 \mathrm{mg}$ of anode material was lost during the test. Pre- and post-test micrographs of the cathode, shown in Figure $22 a$ and $22 b$ revealed the same trends as previously noted.

\section{Cycles 401-500}

Cathode " $E$ " was installed and the mass flow rate reduced to $30 \mathrm{mg} / \mathrm{s}$. Ejection of molten material was evident during startup, and the strip chart record of Figure 23 clearly shows instabilities in the arc voltage. The arc voltage excursions were of larger amplitude than those of the previous tests, and interestingly, seemed to settle out when the arc current was increased to the final value.
Chamfering of the constrictor was evident over the entire circumference, as shown in the micrographs of the converging section in Figure 24a. The arc textured region increased in diameter to $2.7 \mathrm{~mm}$, but the constrictor diameter remained at $0.46 \mathrm{~mm}$. after 500 starts. The micrograph of the diverging section, shown in Figure $24 \mathrm{~b}$ showed deposition of material distributed over the entire surface, corresponding to the complete chamfering of the constrictor. Anode weight remained unchanged. The pre and post-test micrographs of the cathode, shown in Figure 25a and 25b again revealed some erosion the cathode tip, and the textured region was significantly larger than in the previous tests. However, less than $1 \mathrm{mg}$ of material was lost from the cathode.

\section{CONCLUSIONS}

The reduced propellant flow rates associated with high performance arcjets have placed new emphasis on electrode erosion, especially at startup. To mitigate electrode damage, a $2-5 \mathrm{~kW}$ arcjet PPU was modified to provide a soft-start current profile for which employed an initial arc current significantly lower than the nominal current for the first eight seconds of operation. Current overshoot at startup was also limited to $25 \%$ of the low current value for the first $30-50 \mathrm{~ms}$ after breakdown. A 500 cycle test using simulated fully decomposed hydrazine was conducted to determine the electrode erosion caused by this current profile during startup. Electrode geometry and mass flow rates were selected based on requirements for a 600 second mission average arcjet system. The flow rate was varied in a stepwise fashion every 100 cycles to simulate the blow down of a flight propellant system, with a beginning of life flow rate of $45 \mathrm{mg} / \mathrm{s}$ and end of life flow of 30 $\mathrm{mg} / \mathrm{s}$. The arcjet was disassembled after each 100 starts, and the anode inspected for damage. A new cathode was installed for each 100 starts to assess cathode erosion at each flow rate. Electrode damage was negligible at flow rates above $33 \mathrm{mg} / \mathrm{s}$, with chamfering of the constrictor occurring at flow rates of $33-30 \mathrm{mg} / \mathrm{s}$. Constrictor diameter remained unchanged however, and the thruster remained operable at the completion of the test. Cathode erosion was minimal, but evidence of initial arc attachment further back from the cathode tip as flow rate was reduced was apparent. The nature of the electrode erosion was such that performance of the thruster would not be adversely affected. The soft-start current profile significantly reduced electrode damage when compared to state of the art starting techniques. 


\section{REFERENCES}

1. Wallner, L.E. and Czika, J. Jr., "Arc-Jet Thrustor for Space Propulsion," NASA TN D-2868, 1965.

2. Todd, J.P., "30 kW Arc-Jet Thrustor Research," Giannini Scientific Corporation, APL-TDR-64-58, March 1964.

3. Ducati, A.C., et. al., "1-kW Arcjet-Engine System Performance Test," Journal of Spacecraft and Rockets, Vol. 1, No. 3, May-June 1964, pp. 327-332.

4. Sarmiento, C.J. and Gruber, R.P., "Low Power Arcjet Thruster Pulse Ignition," AIAA 87-1951, (NASA TM-100123), June 1987.

5. Gruber, R.P., "Power Electronics for a $1 \mathrm{~kW}$ Arcjet Thruster," AIAA 86-1507, (NASA TM-87340), June 1986.

6. Curran, F.M. and Haag, T.W., "Arcjet Component Conditions Through a Multistart Test," AIAA 87-1060, (NASA TM-89857), May 1987.

7. Smith, R.D., Roberts, C.R., Davies, K., and Vaz, J., "Development and Demonstration of a $1.8 \mathrm{~kW}$ Hydrazine Arcjet Thruster," AIAA 90-2547, July 1990.

8. Gruber, R.P., Gott, R.W., and Haag, T.W., "5 kW Arcjet Power Electronics," AIAA Paper 89-2725, (NASA TM-102108), July 1989.

9. Hamley, J.A. and Hill, G.M., "Power Electronics for Low Power Arcjets," AIAA Paper 91-1991, (NASA TM-104459), July 1991.

10. Hamley, J.A., Pinero, L.R., and Hill, G.M., "10 kW Power Electronics for Hydrogen Arcjets," Proceedings of the 1992 JANNAF Propulsion Meeting, pp. 539-553, (NASA TM-105614), February 1992.

11. Wong, S. et. al. "Operational Testing of the Power Conditioning Unit for a $30 \mathrm{kWe}$ Arcjet," Proceedings of the Eighth Symposium on Space Nuclear Power Systems, pp. 982-987, M.S. El-Genk and M.D. Hoover, eds., American Institute of Physics, New York, 1991.

12. Lichon, P.J., Private Communication, Rocket Research Corporation, March, 1993.
13. Curran, F.M. and Haag,- T.M., "Extended Life and Performance Test of a Low-Power Arcjet," Joumal of Spacecraft and Rockets, Vol. 29, No. 4, July-August 1992, pp. 444-452.

14. Lichon, 'P.J., and Sankovic, J.M., "Development and Demonstration of a 600 Second Mission Average Arcjet," To be presented at the 23rd. IEPC, Seattle Washington, September, 1993. 
Table I. Specific impulse and flow rates used for each 100 cycle test segment

$\begin{array}{ccc}\text { Cycle } & \text { Isp, } \mathrm{s} & \text { Flow Rate, } \mathrm{mg} / \mathrm{s} \\ & & \\ 1-100 & 570 & 45 \\ 101-200 & 585 & 41 \\ 201-300 & 605 & 37 \\ 301-400 & 620 & 33 \\ 401-500 & 630 & 30\end{array}$

Table II. Pre and Post test electrode masses for each 100 cycle test segment

Pre Test Post test Pre Test Post Test

Cycles Cathode Cathode mass, g Cathode mass, g Anode mass, g Anode mass, g

$\begin{array}{rlllll}1-100 & \text { A } & 29.3887 & 29.3884 & 30.3088 & 30.3084 \\ 101-200 & \text { B } & 30.4014 & 30.4009 & 29.3463 & 29.3462 \\ 201-300 & \text { C } & 30.0751 & 30.0749 & 29.3304 & 29.3302 \\ 301-400 & \text { D } & 30.1933 & 30.1931 & 29.3107 & 29.3103 \\ 401-500 & \text { E } & 30.3736 & 30.3738 & 29.2887 & 29.2893\end{array}$

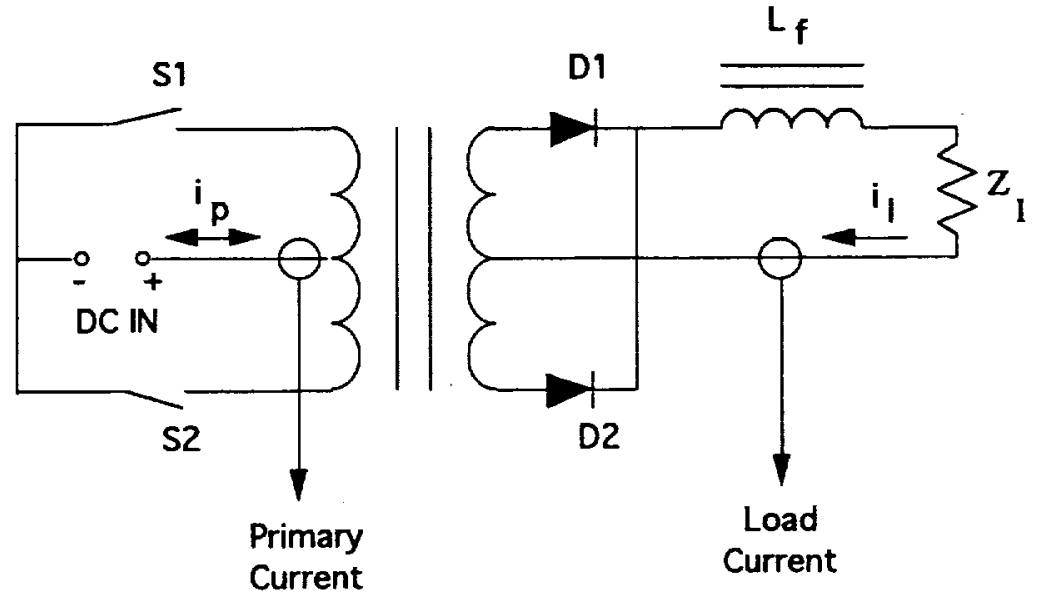

Figure 1. Simplified schematic of Push-Pull topology showing locations of current sensors for current-mode control 


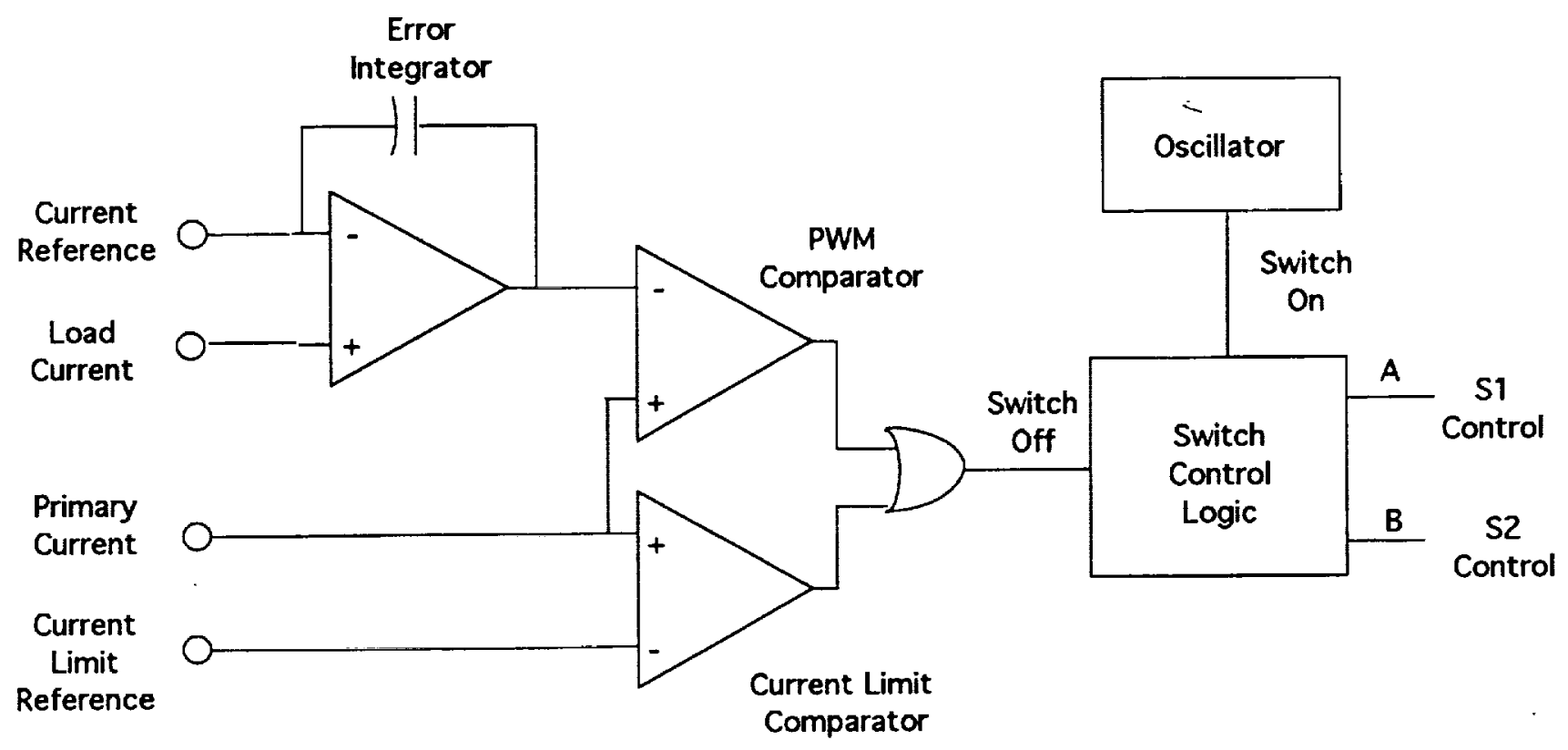

a.) Current Mode PWM controller block diagram.

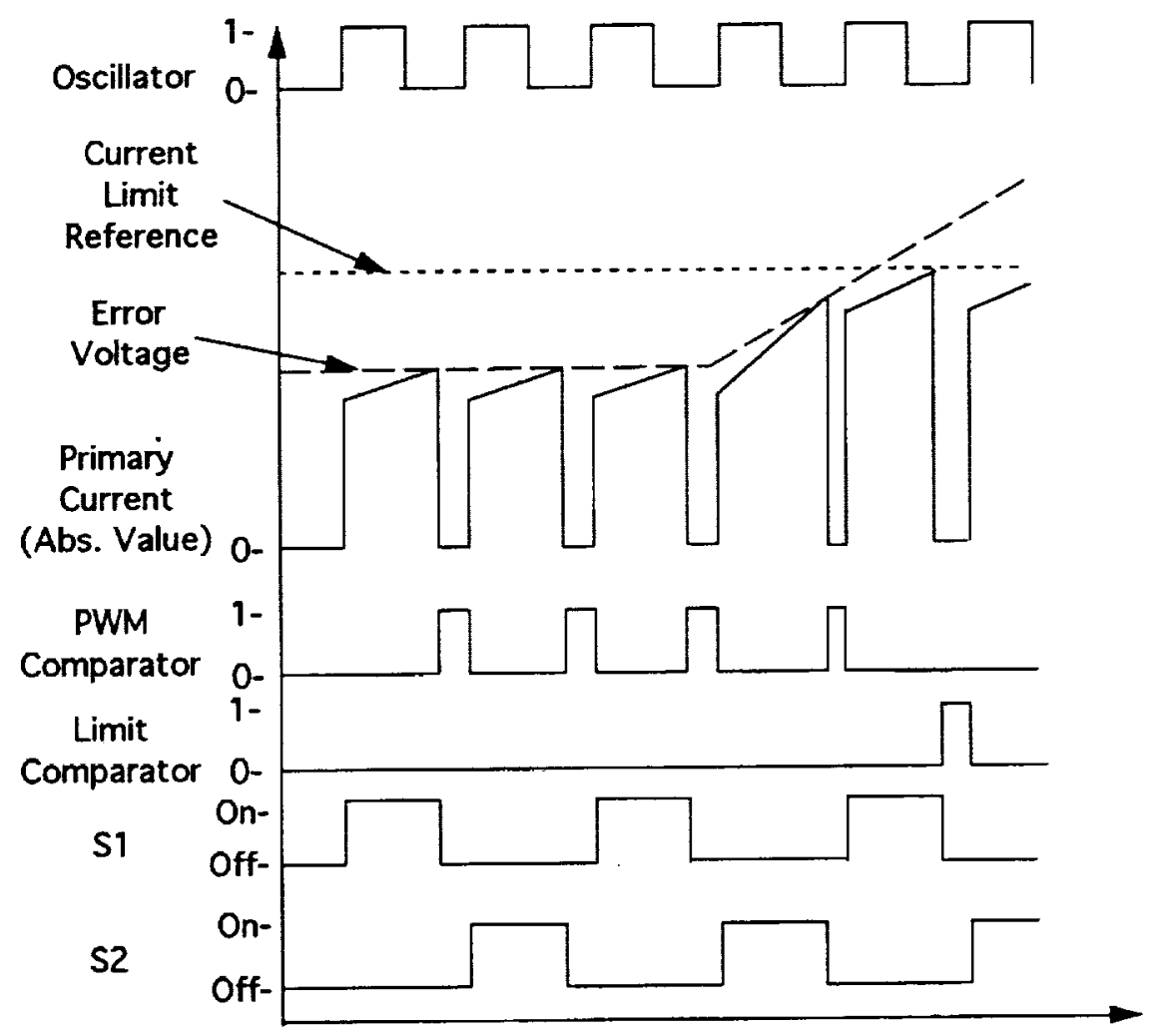

b.) PWM control waveforms

Figure 2. Simplified block diagram of current mode PWM controller with control waveform timing diagram 


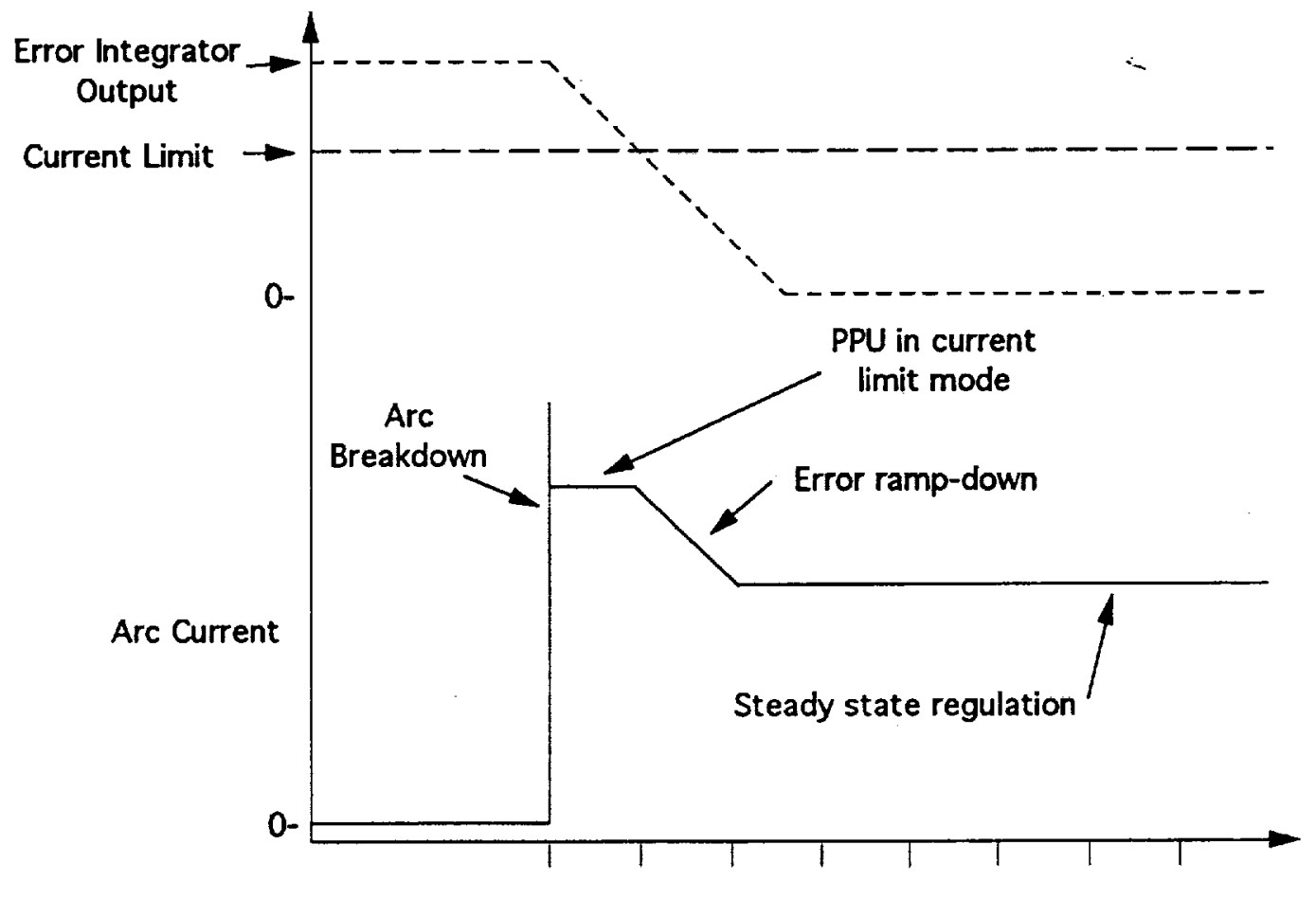

Time, 5ms/Div.

Figure 3. Typical arcjet start showing current limit reference, error integrator output and resulting arc current

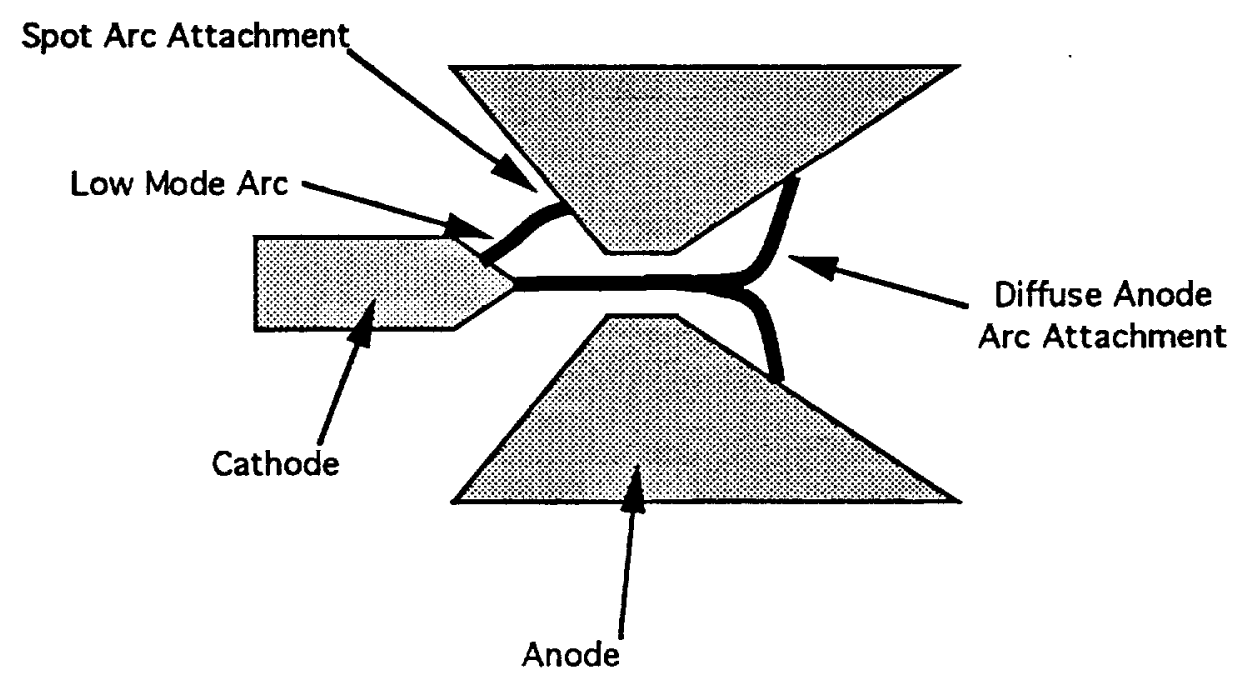

Figure 4. Arcjet electrodes showing "low mode" spot arc attachment and normal mode diffuse arc attachment. 


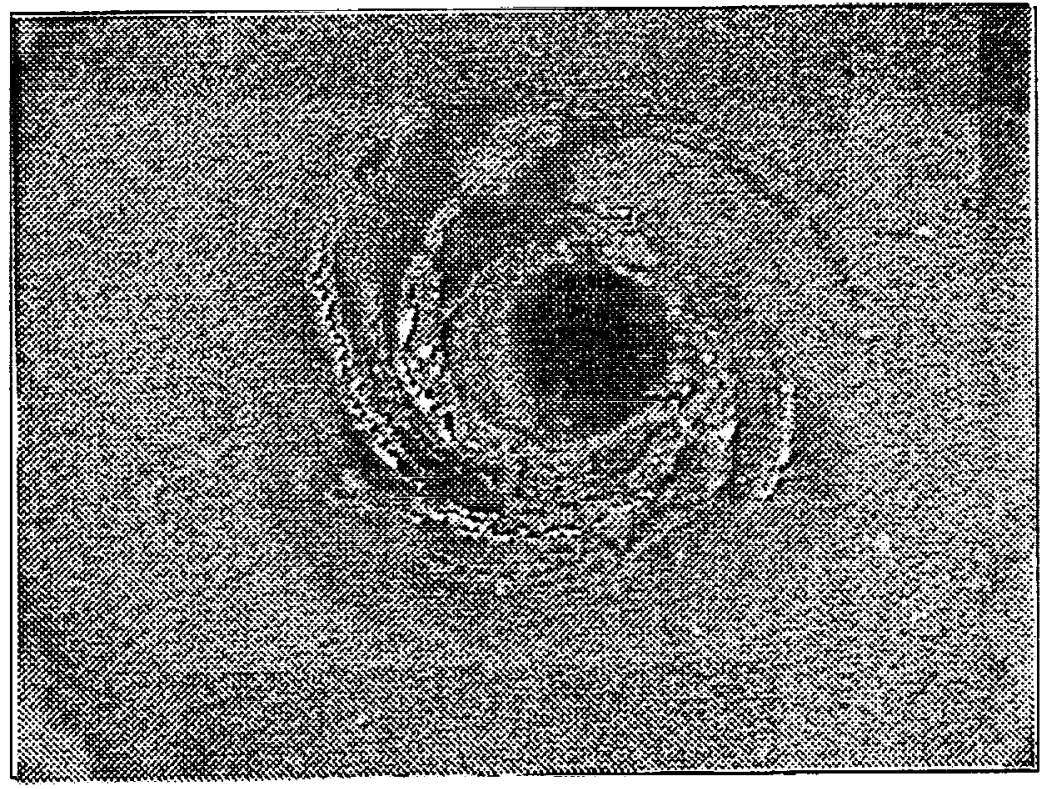

Figure 5. Arcjet anode convergent section with damage from high current starts at low mass flow rates. (Reference 12)

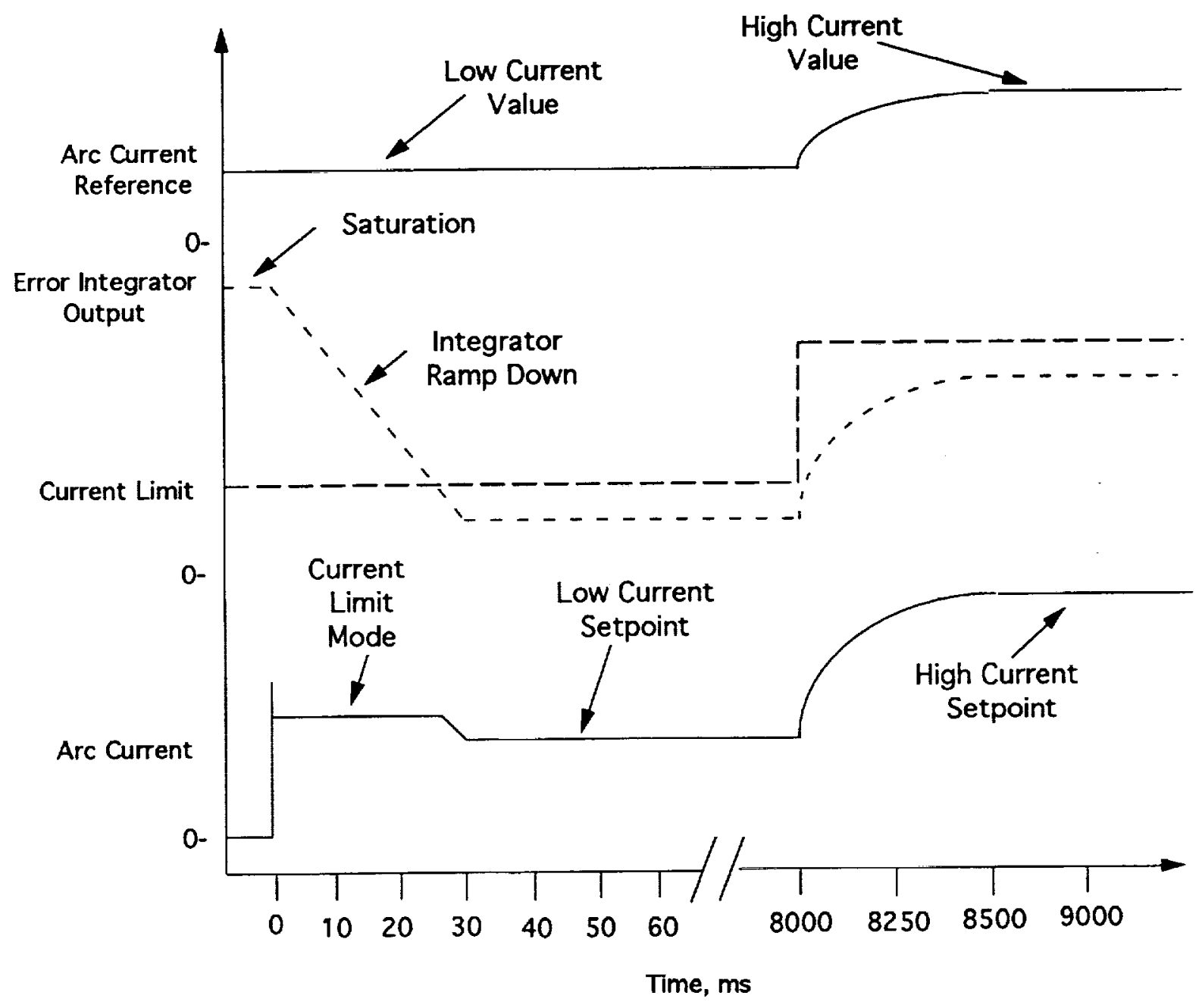

Figure 6. Typical arcjet start with soft start algorithm using bi-level arc current and limit references 


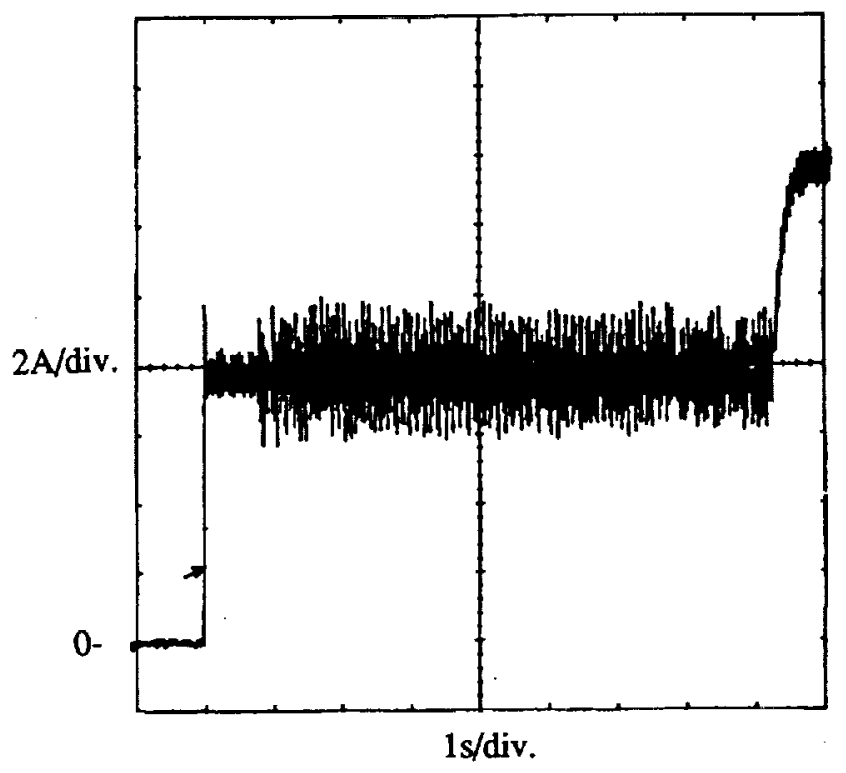

Figure 7. PPU output during arcjet ignition.

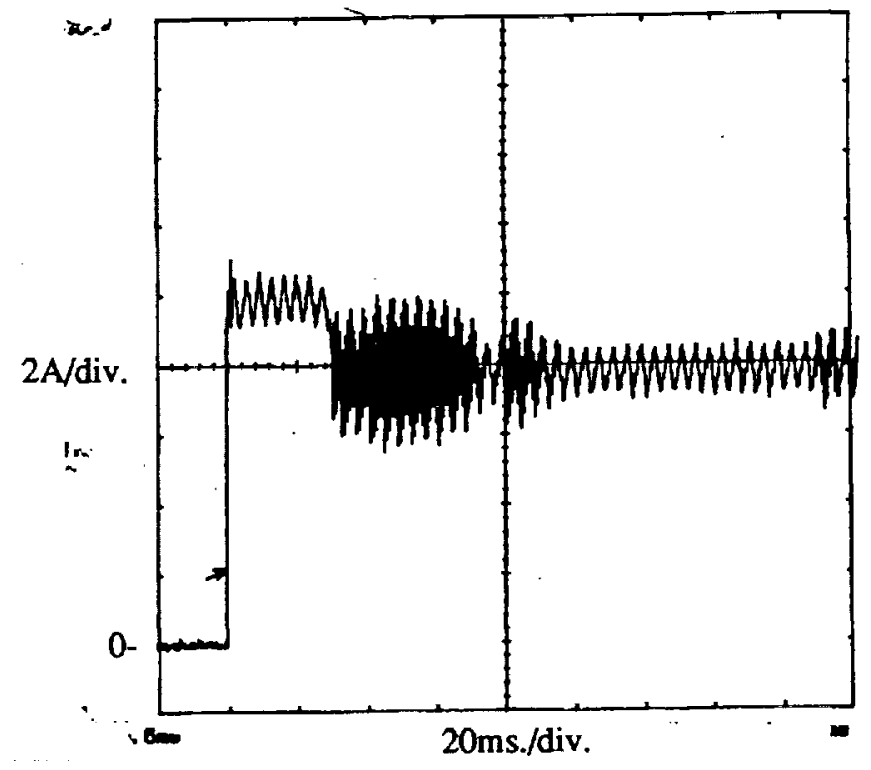

Figure 8. Arc current during first $180 \mathrm{~ms}$. of operation

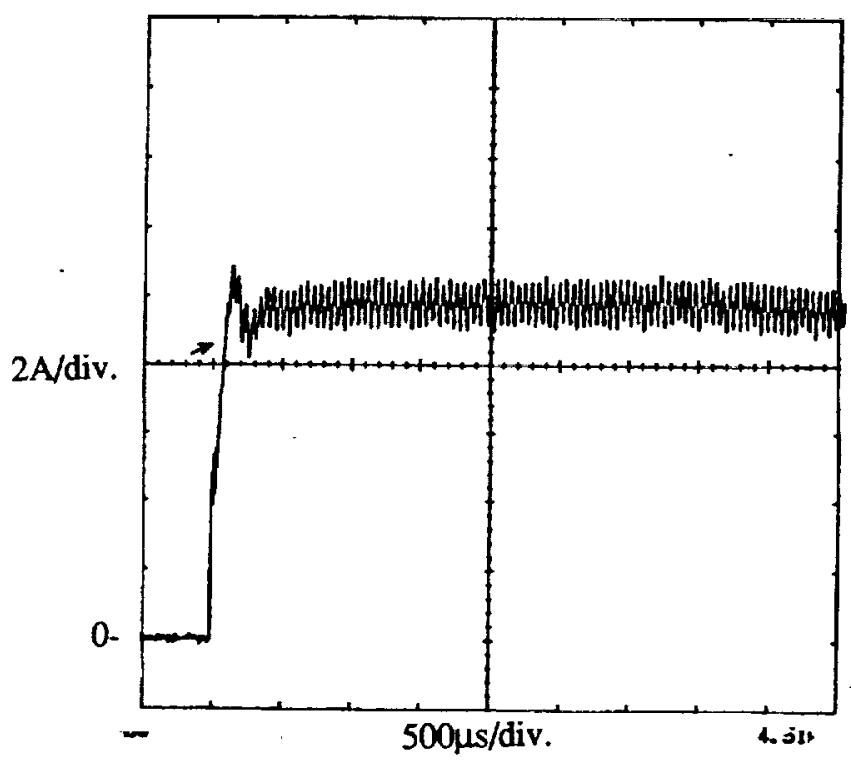

Figure 9. Arc current at breakdown 


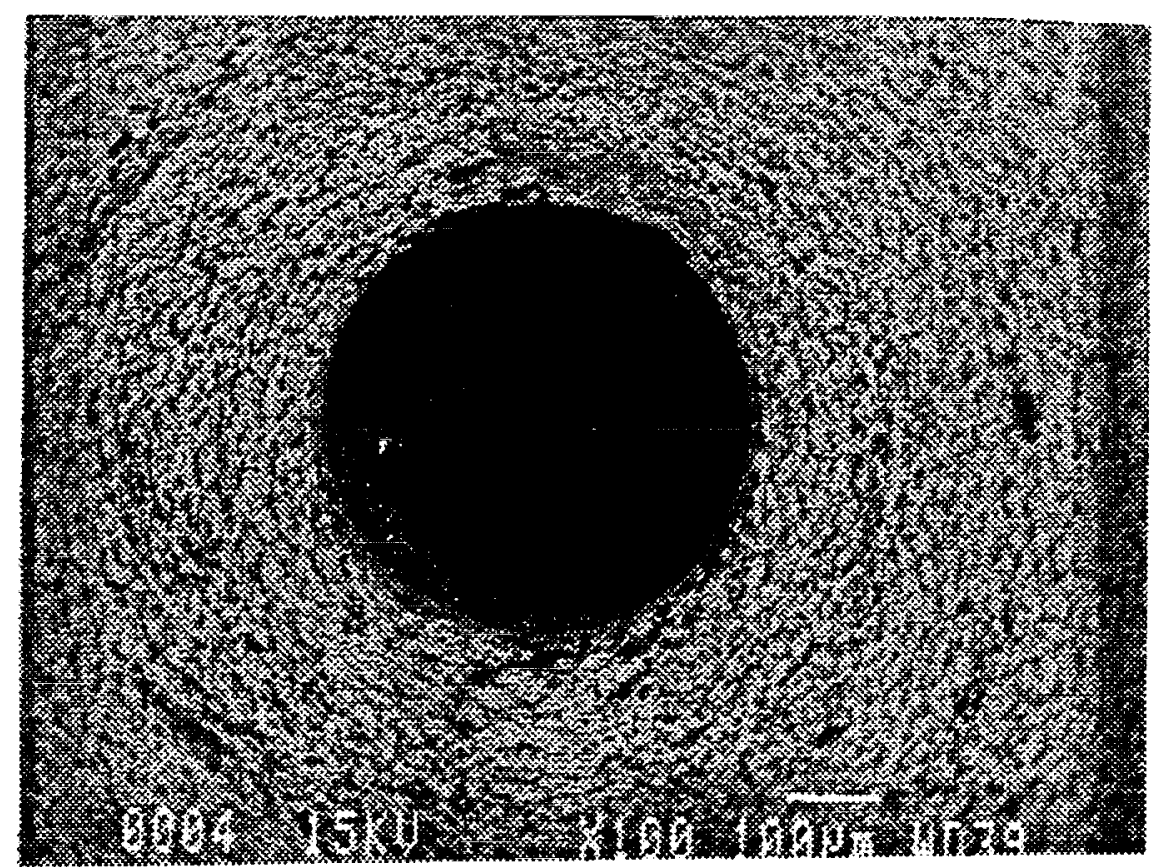

a.) convergent section

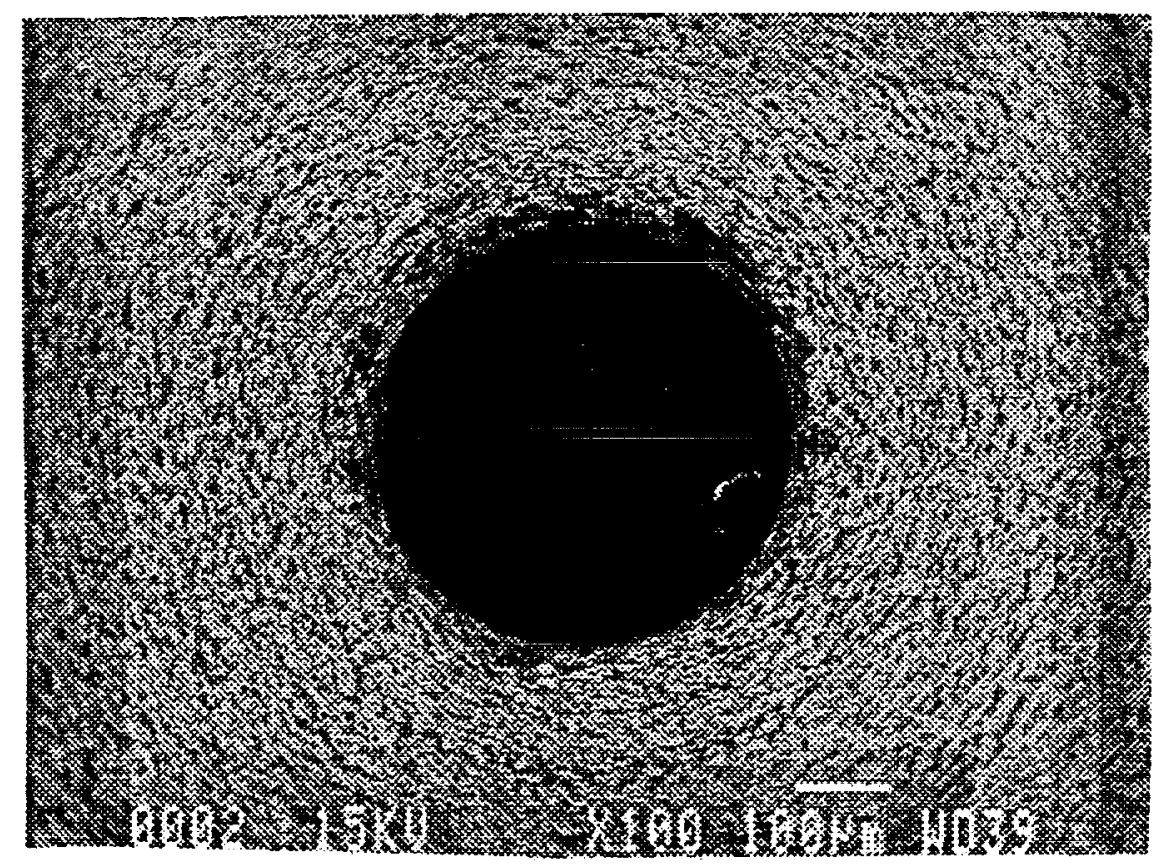

b.) divergent section

Figure 10. Pre-test micrographs of arcjet anode. 


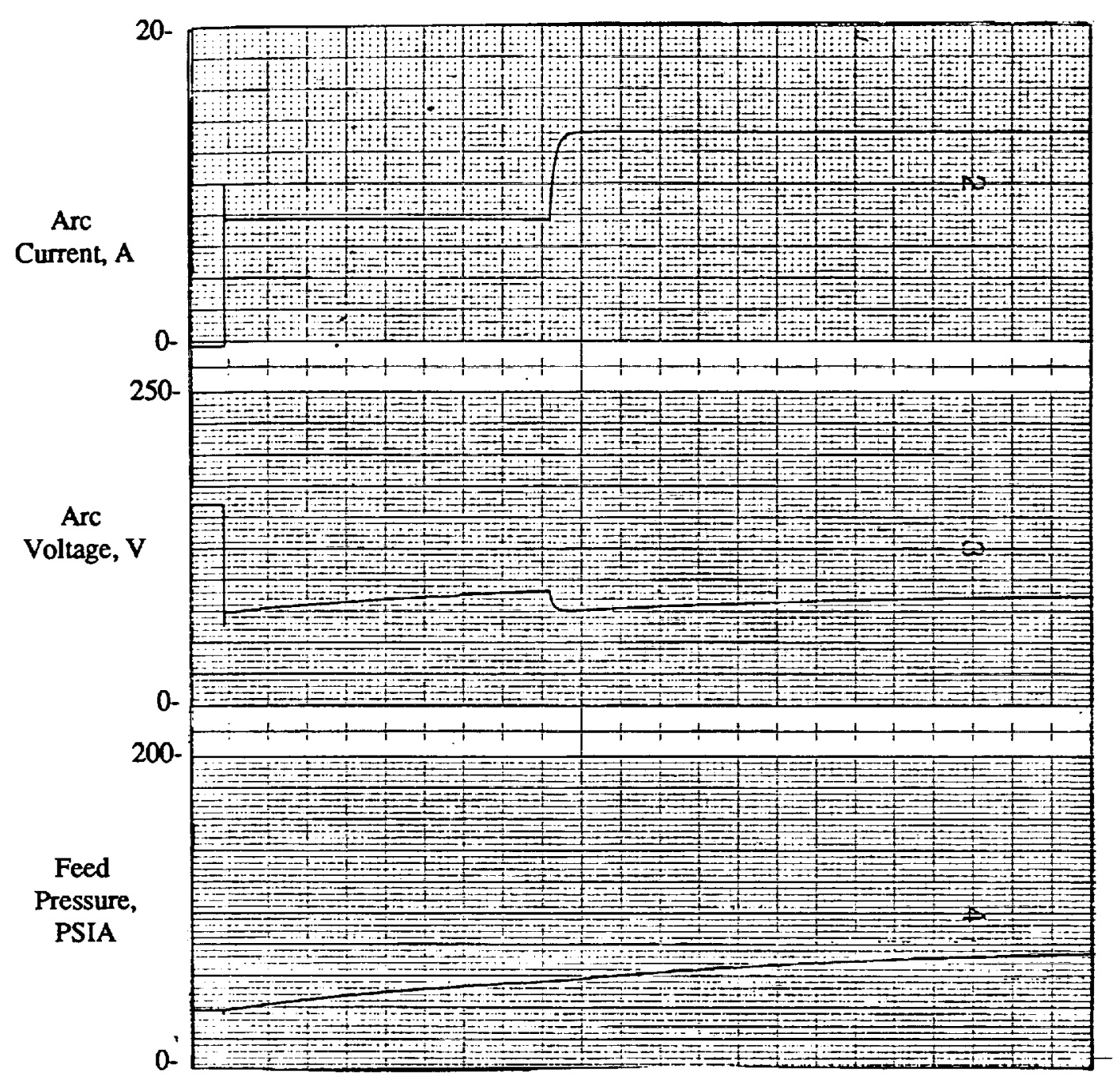

Time, 1 second/division

Figure 11. Arc current, voltage and feed pressure for cycle $1,45 \mathrm{mg} / \mathrm{s}$ flow 


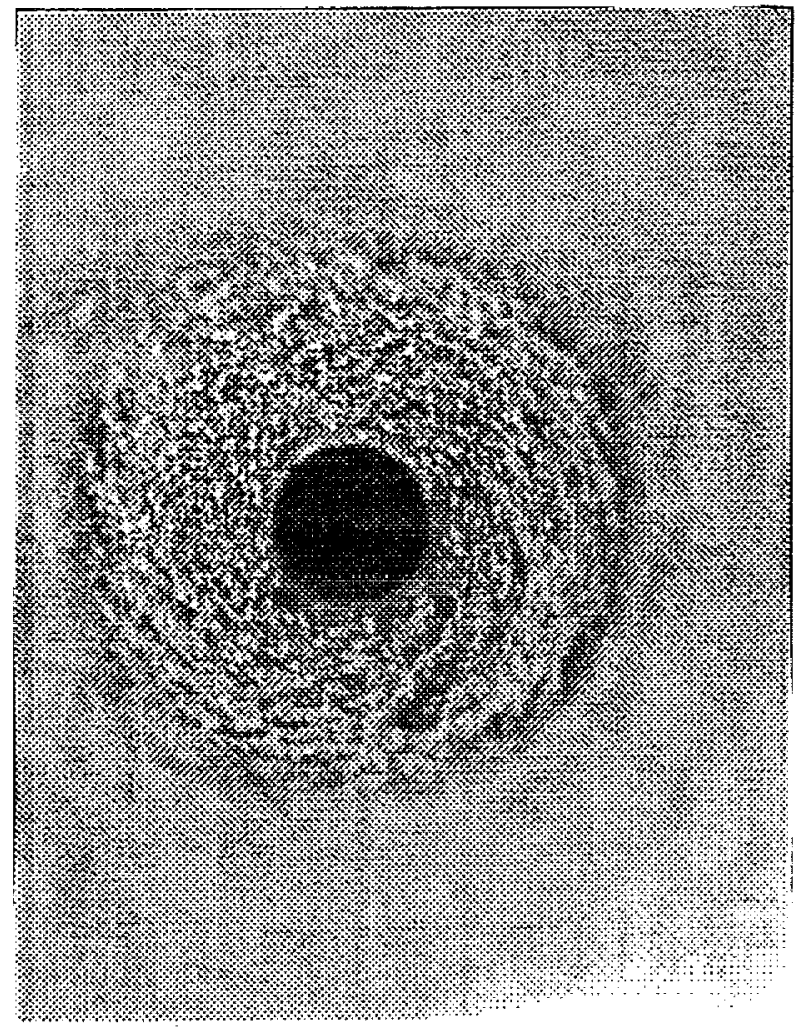

a.) convergent section.

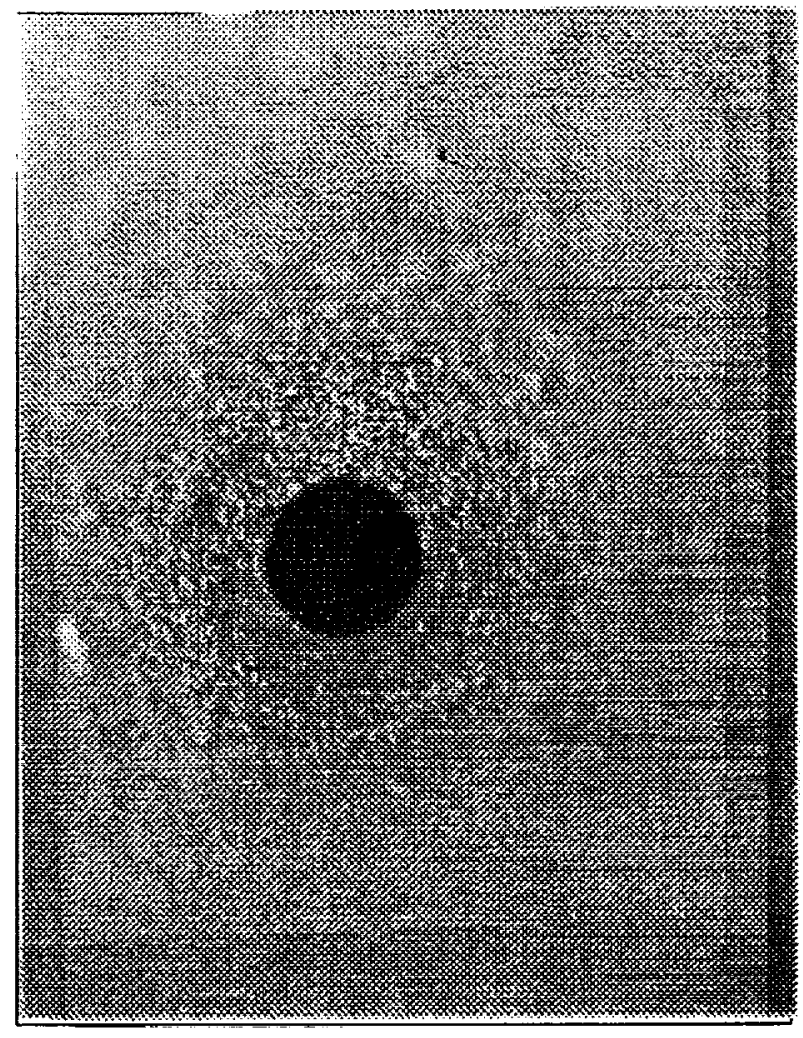

b.) divergent section

Figure 12. Post-test micrographs of the arcjet anode after 100 cycles. $35 \mathrm{X}$ magnification.

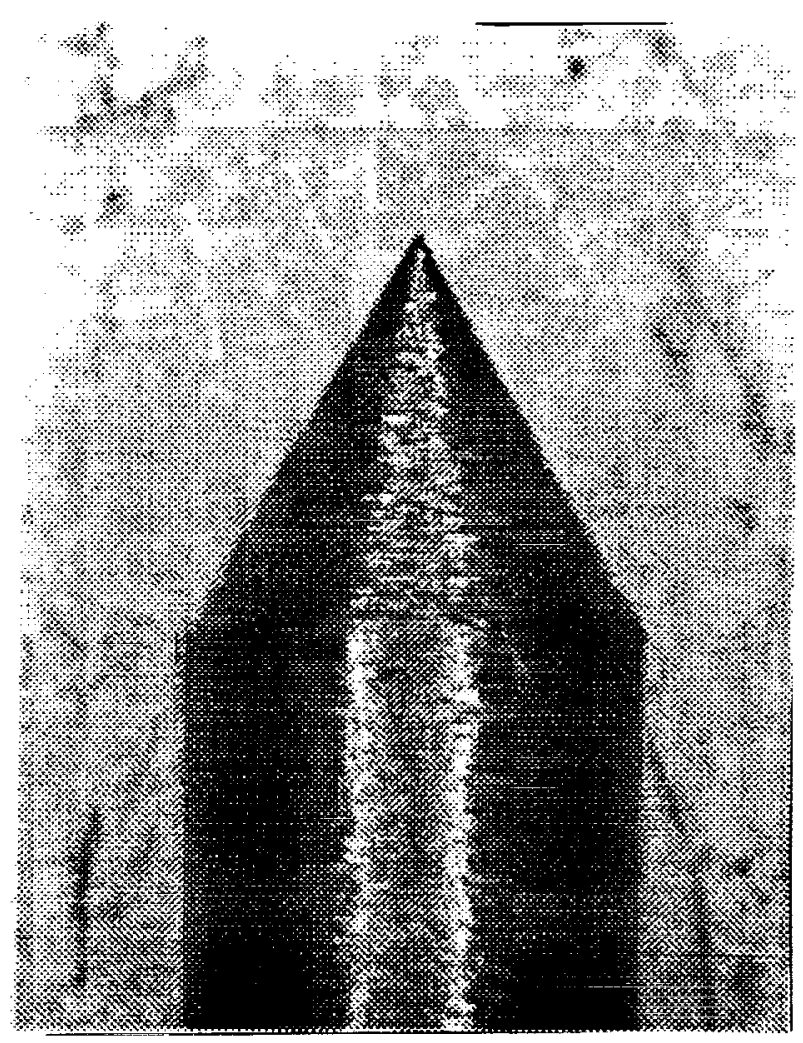

a.) Pre-test

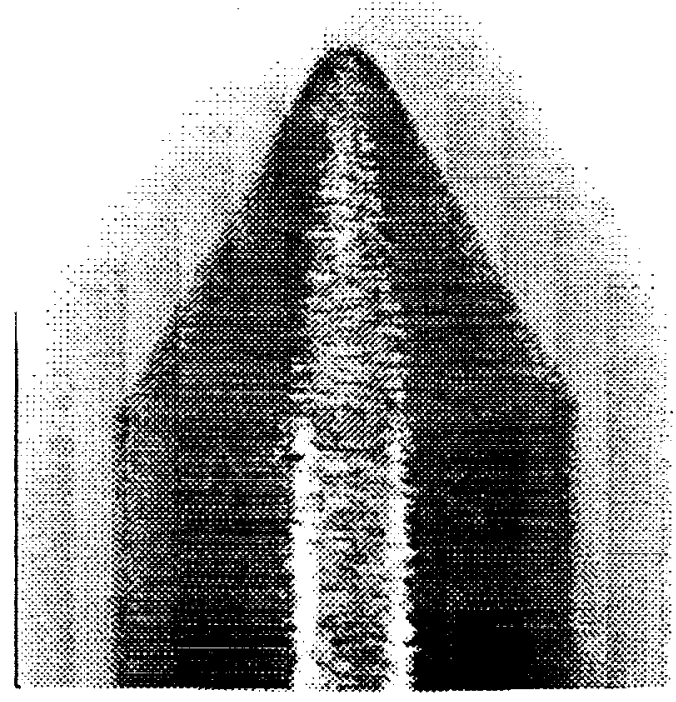

b.) Post-test

Figure 13. Pre- and post-test micrographs of cathode "A," cycles 1-100, 15X magnification 


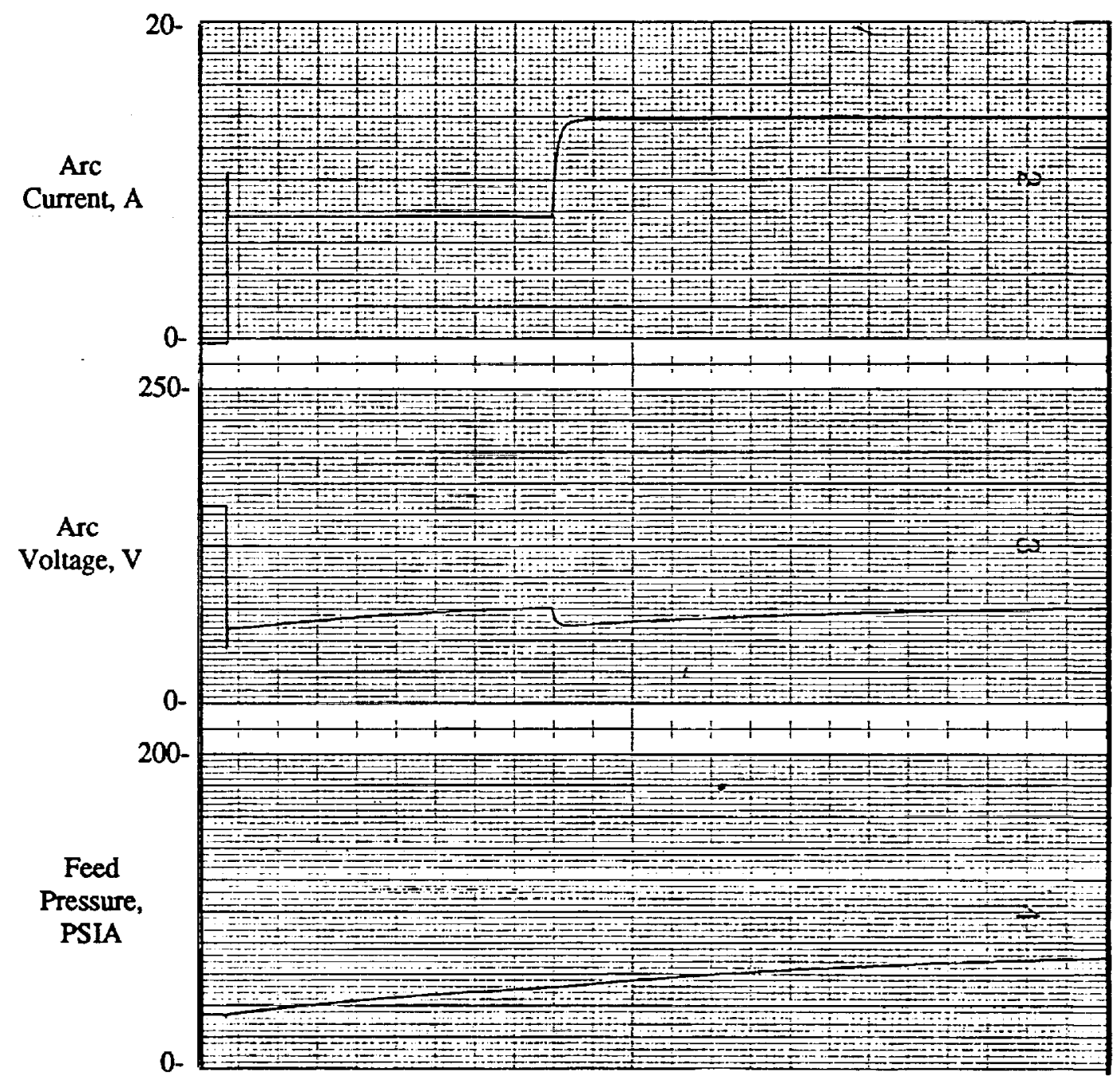

Time, 1 second/division

Figure 14. Arc current, voltage and feed pressure for cycle $101,41 \mathrm{mg} / \mathrm{s}$ flow 


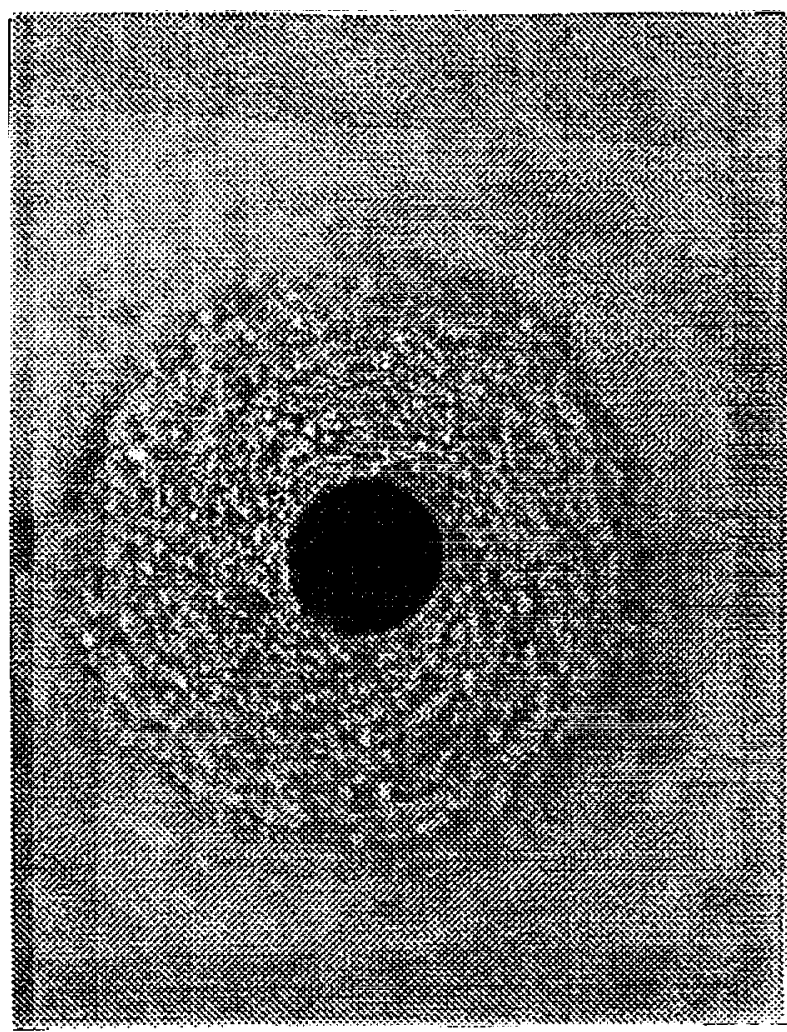

a.) convergent section.

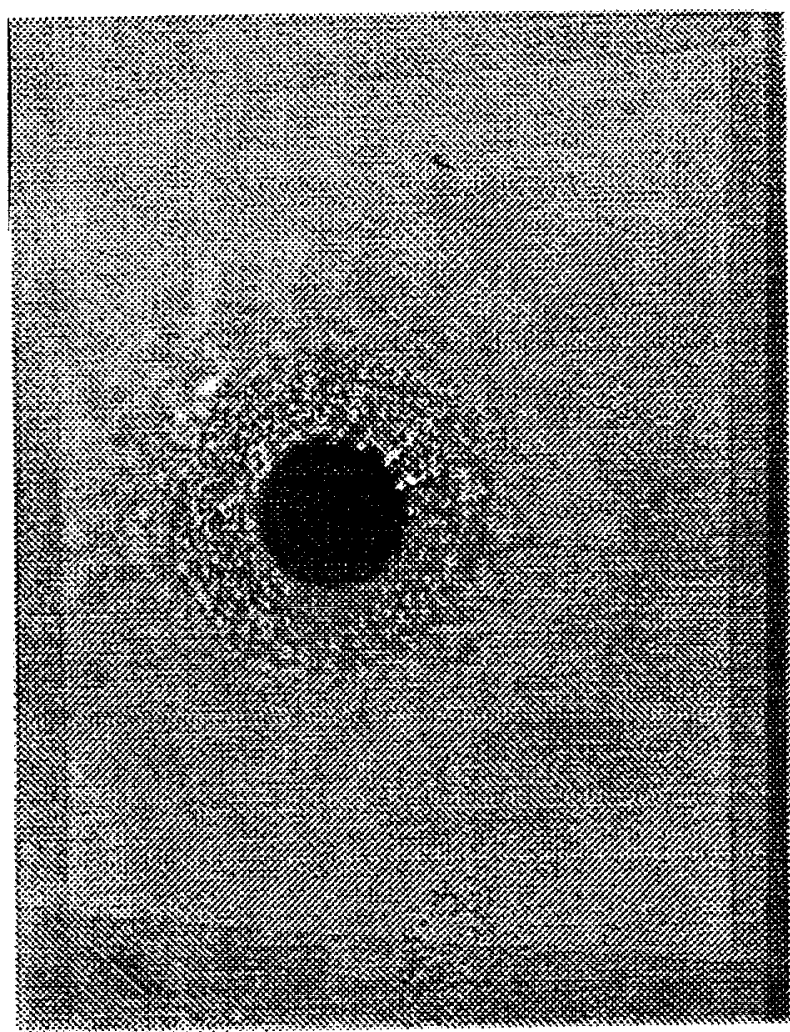

b.) divergent section

Figure 15. Post-test micrographs of the arcjet anode after 200 cycles. $35 \mathrm{X}$ magnification.

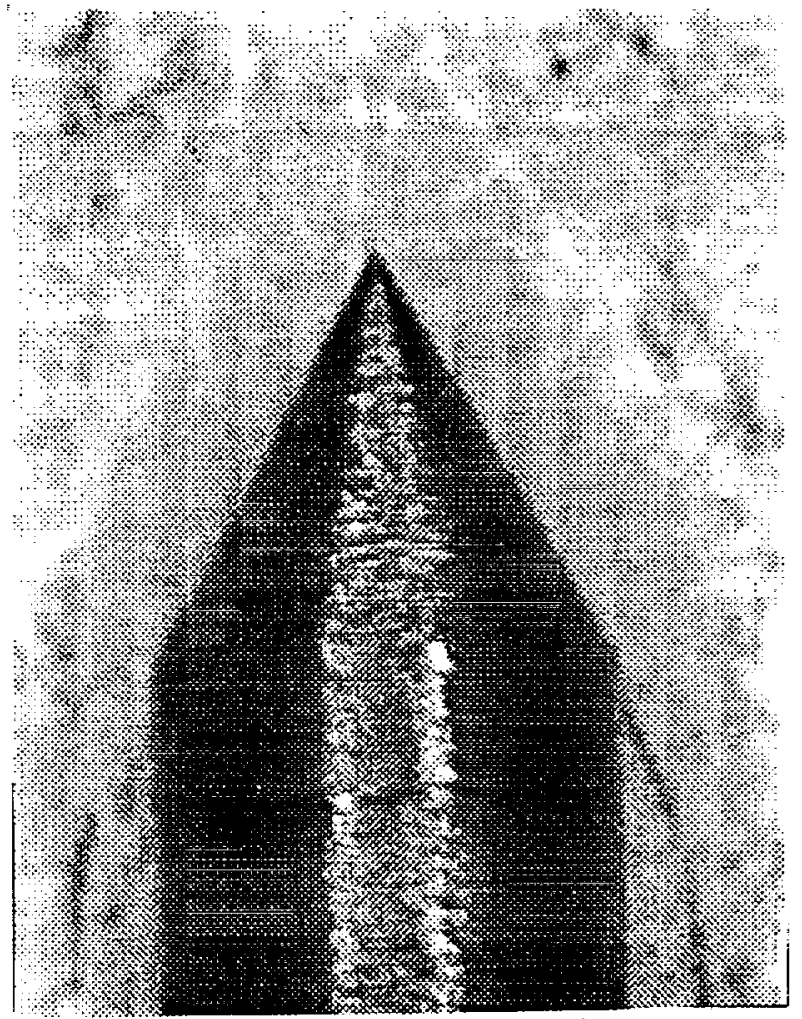

a.) Pre-test

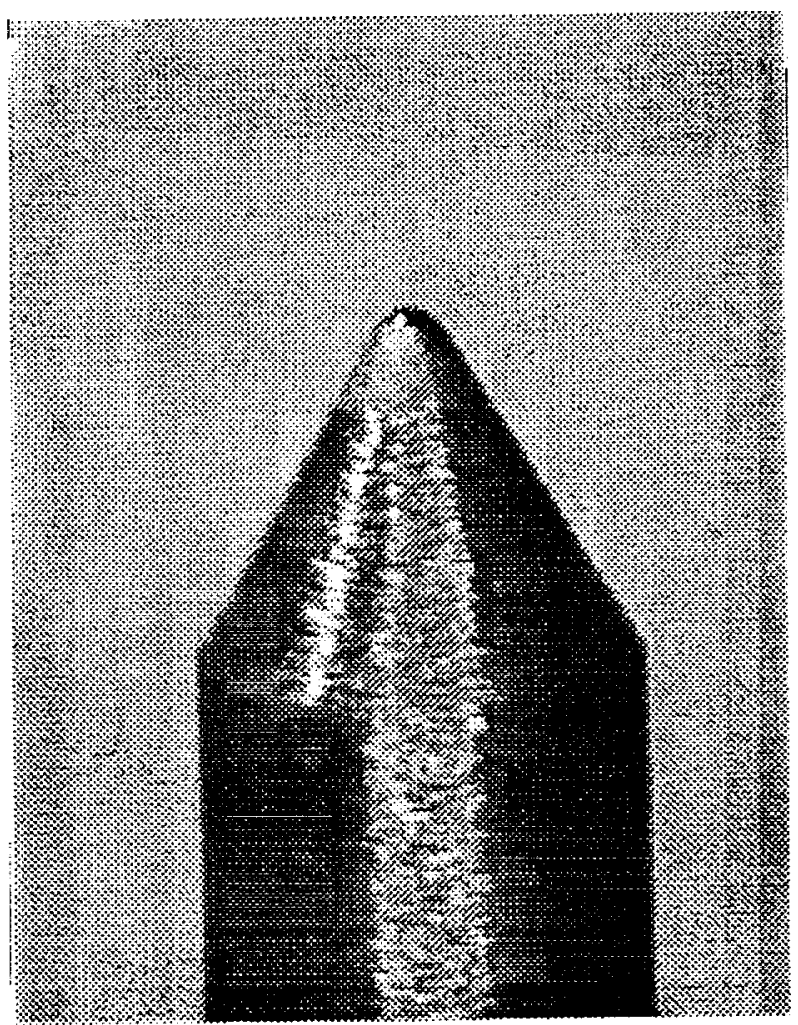

b.) Post-test

Figure 16. Pre- and post-test micrographs of cathode "B," cycles 101-200, 15X magnification. 


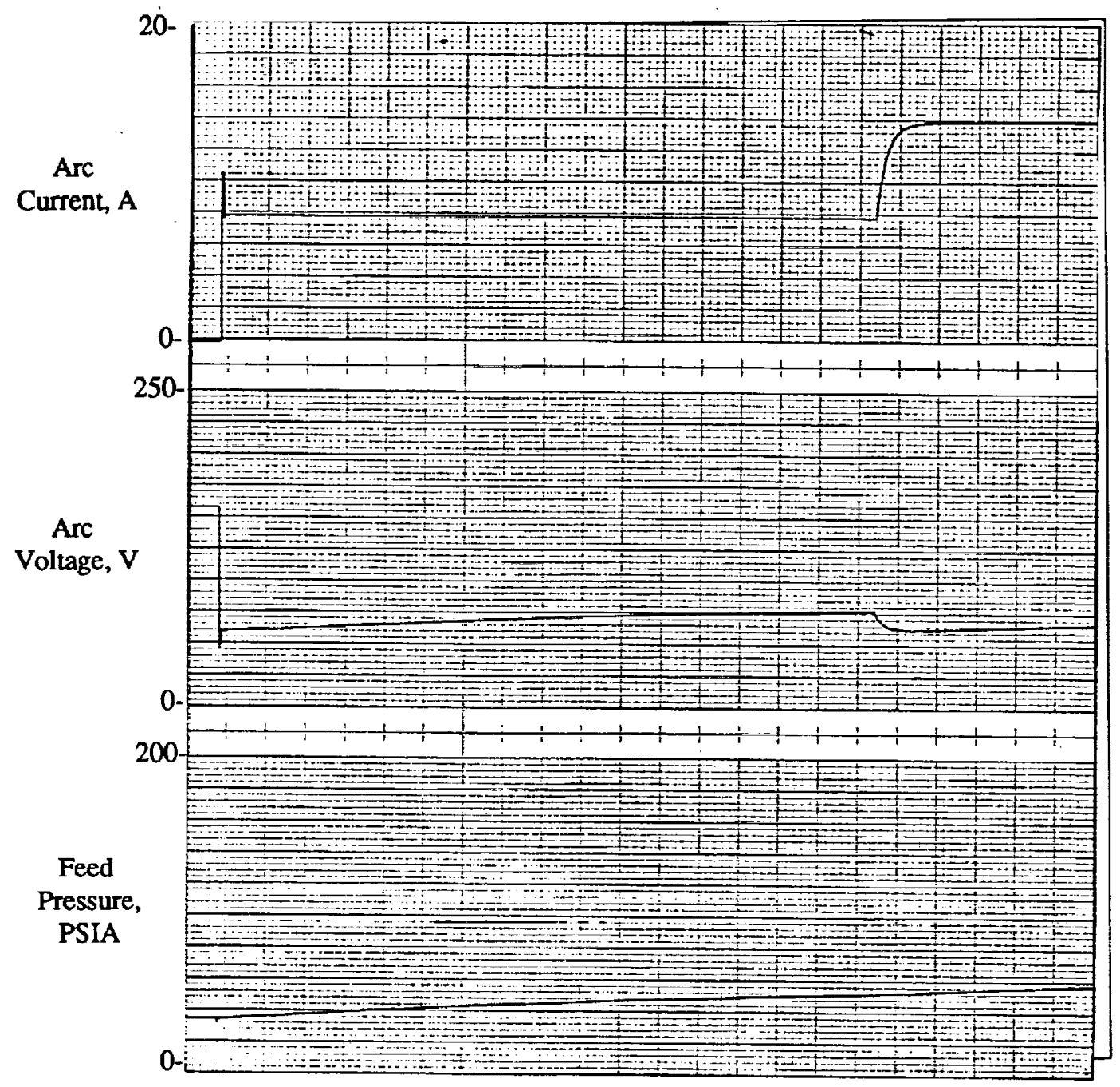

Time, 0.5 second/division

Figure 17. Arc current, voltage and feed pressure for cycle $201,37 \mathrm{mg} / \mathrm{s}$ flow 


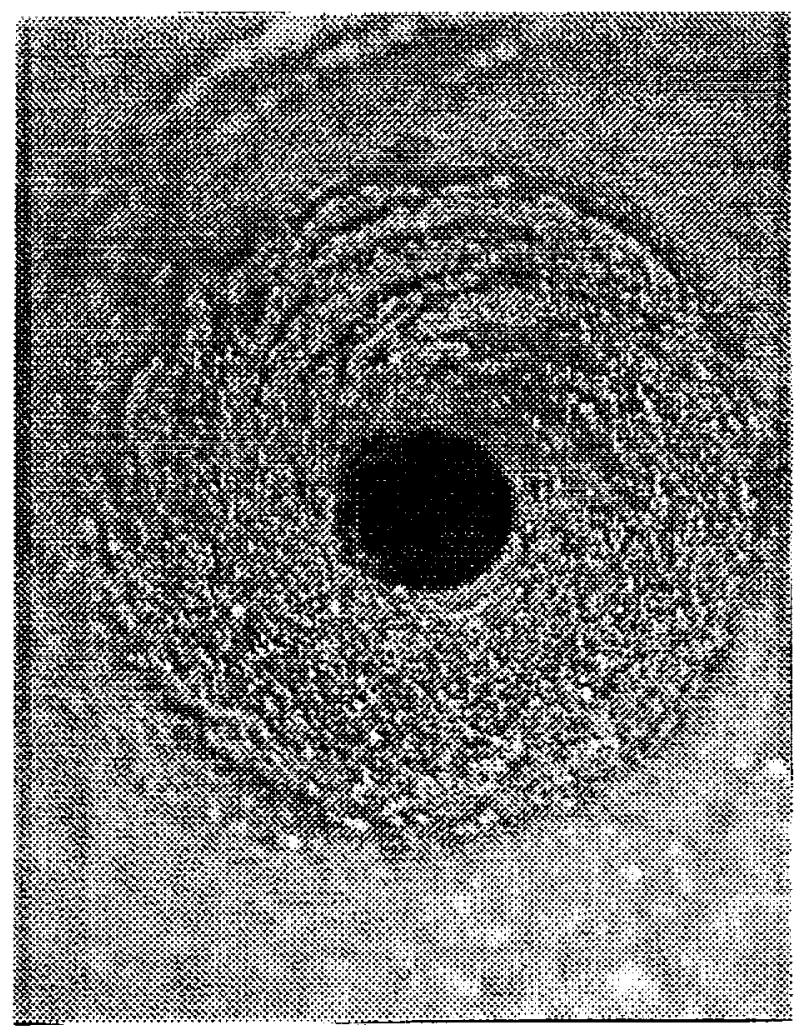

a.) convergent section.

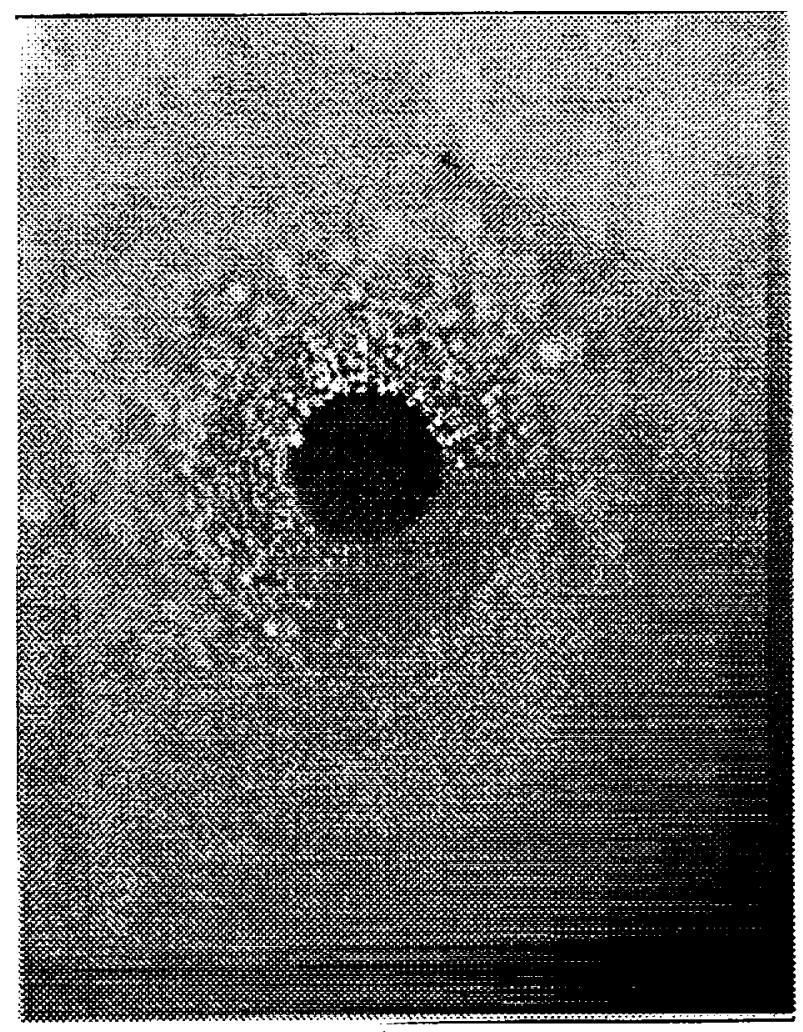

b.) divergent section

Figure 18. Post-test micrographs of the arcjet anode after 300 cycles. $35 \mathrm{X}$ magnification.

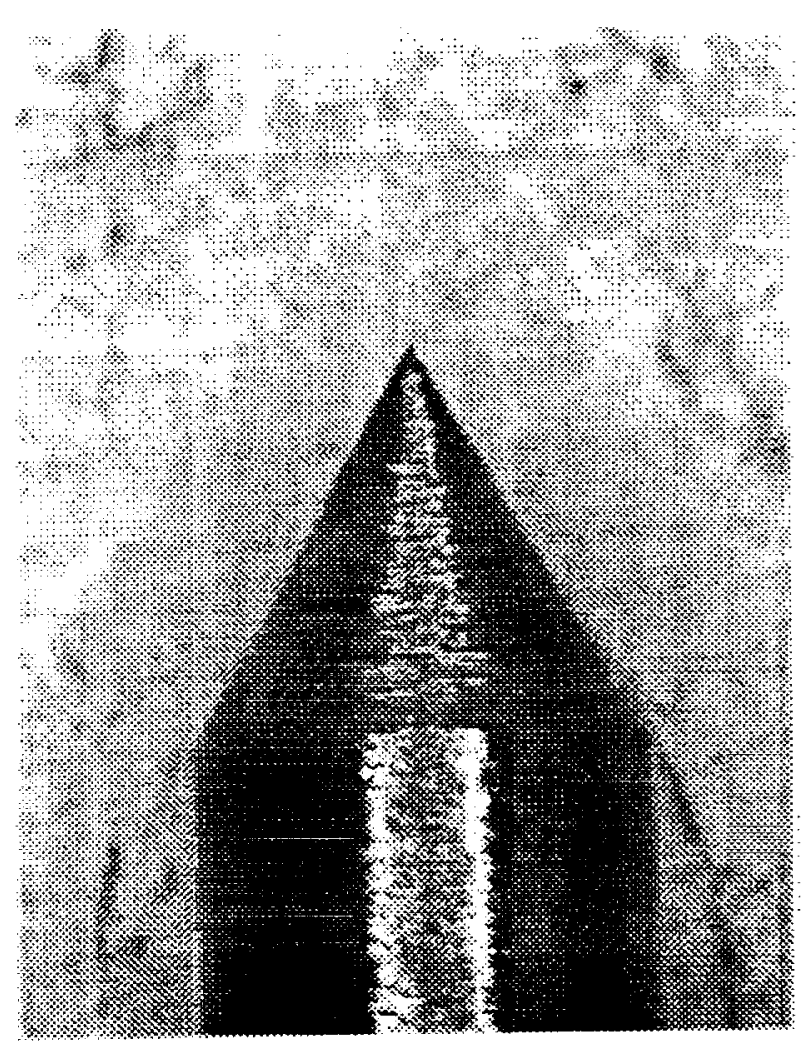

a.) Pre-test

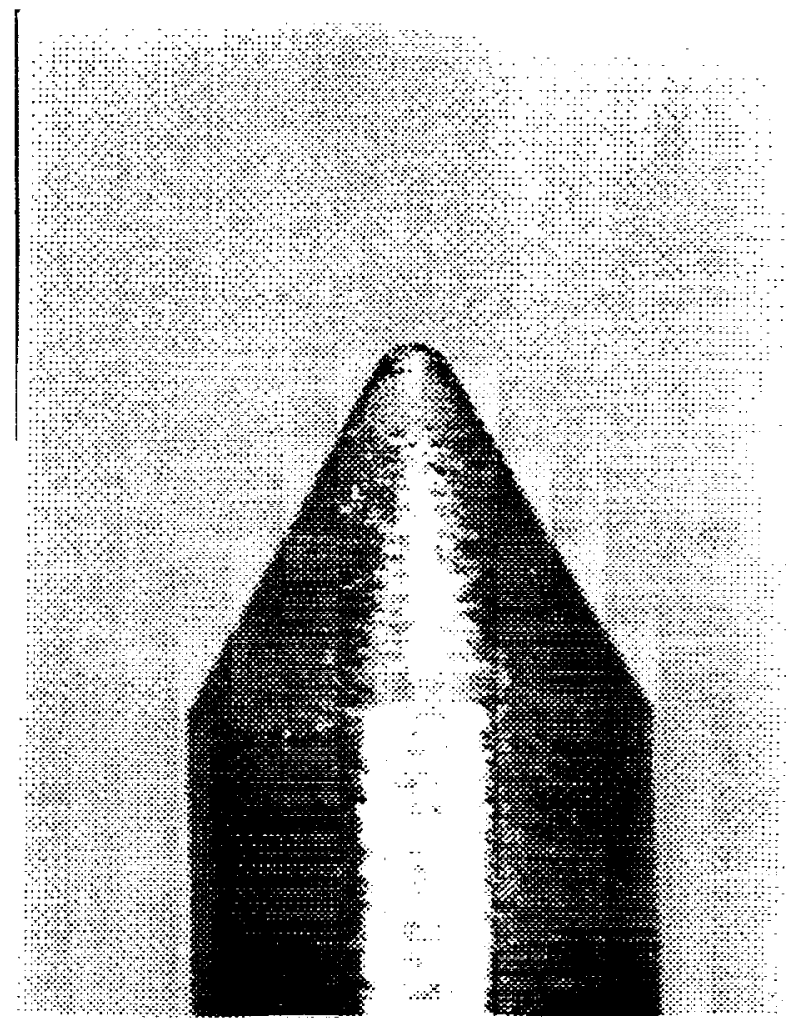

b.) Post-test

Figure 19. Pre- and post-test micrographs of cathode "C," cycles 201-300, 15X magnification 




Time, 1 second/division

Figure 20. Arc current, voltage and feed pressure for cycle $301,33 \mathrm{mg} / \mathrm{s}$ flow 


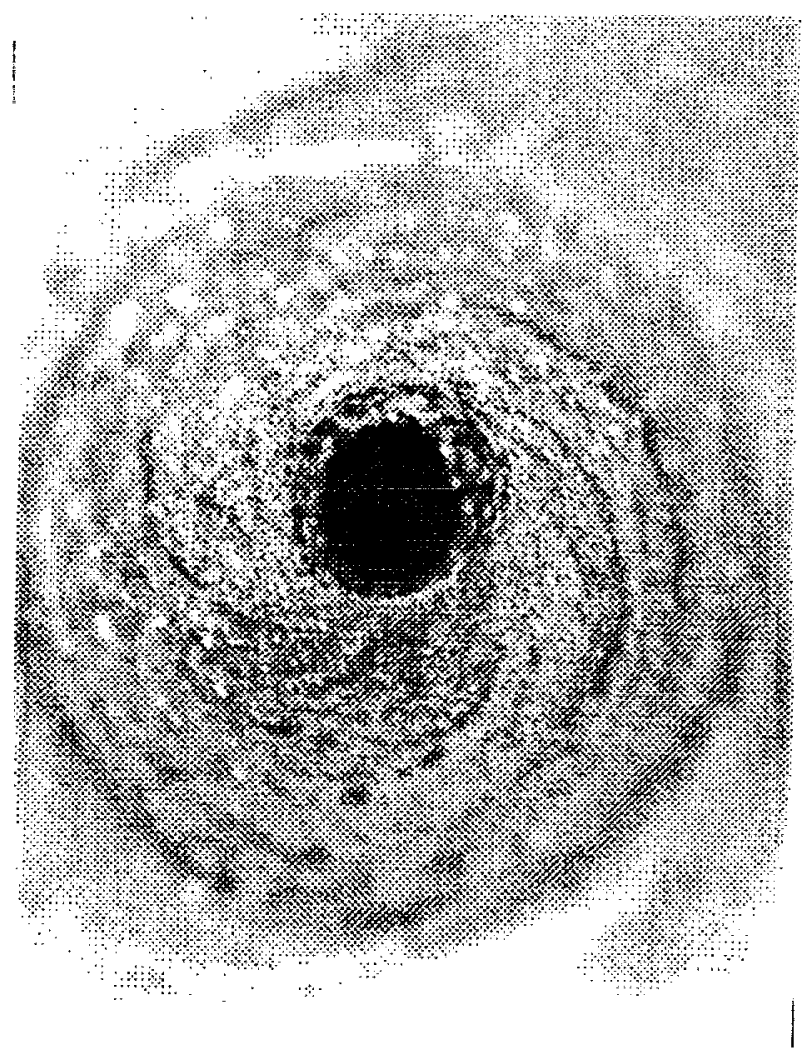

a.) convergent section.

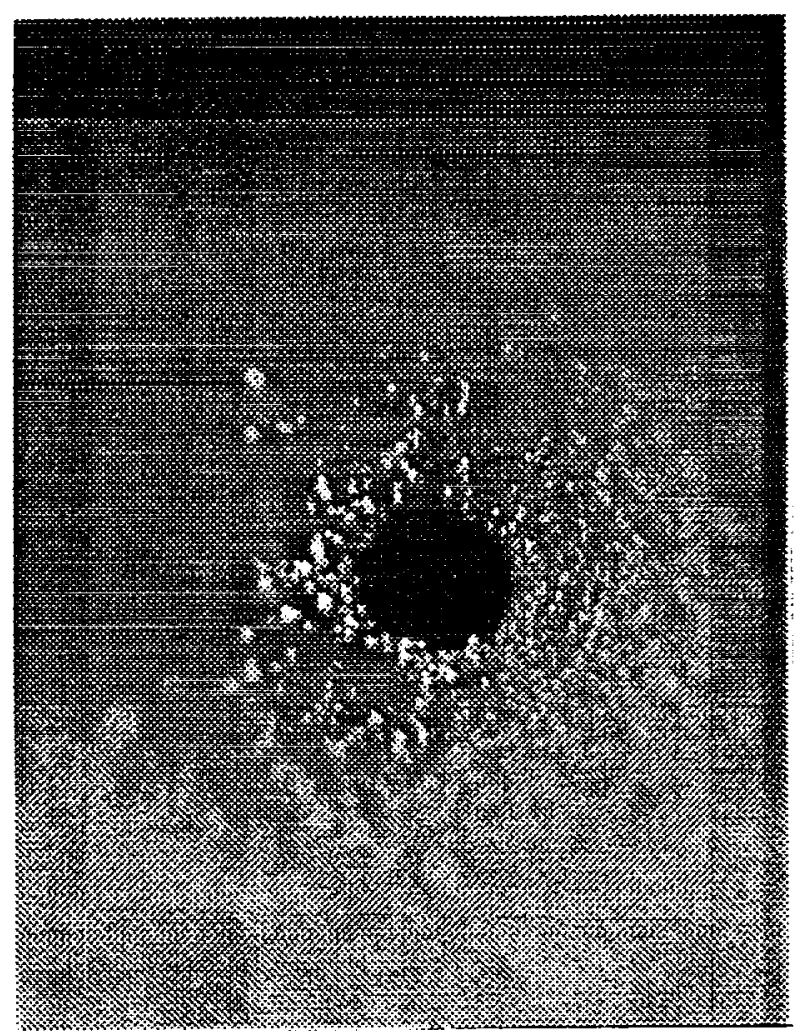

b.) divergent section

Figure 21. Post-test micrographs of the arcjet anode after 400 cycles. $35 \mathrm{X}$ magnification.

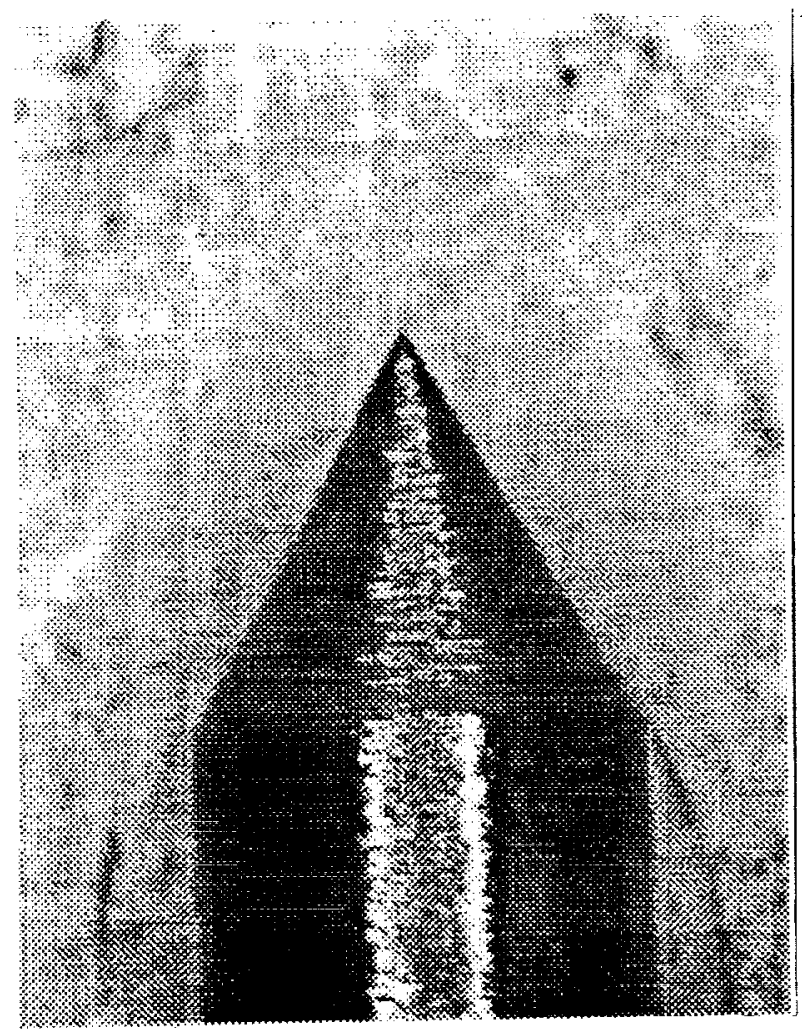

a.) Pre-test

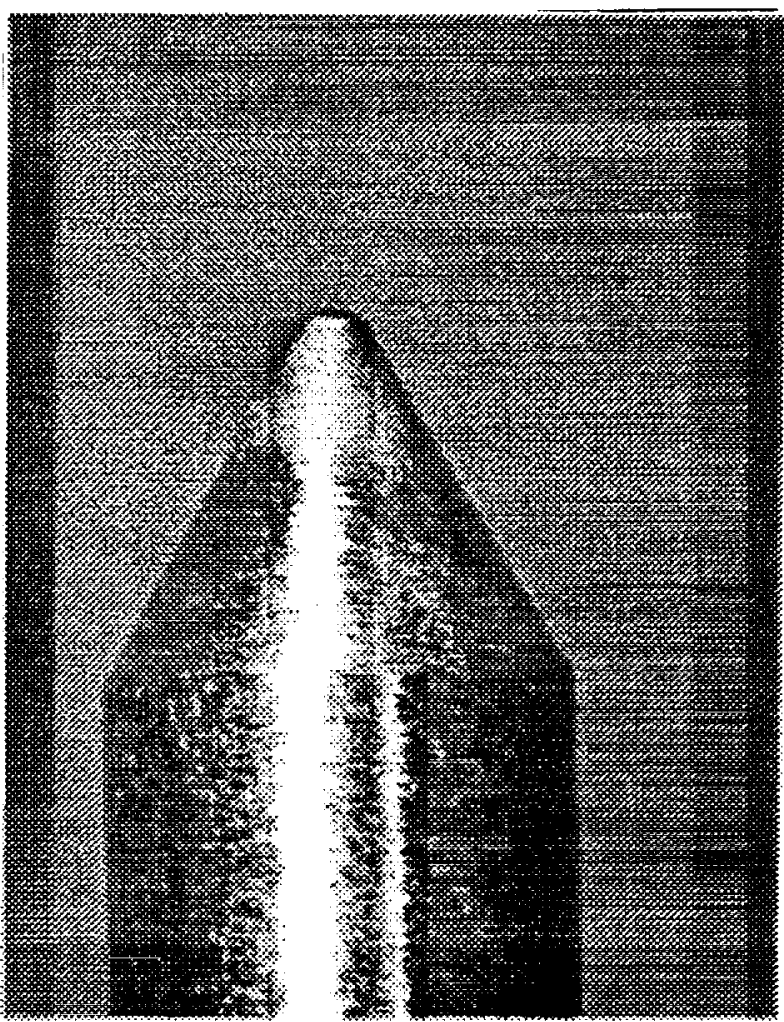

b.) Post-test

Figure 22. Pre- and post-test micrographs of cathode " $D$," cycles $301-400,15 X$ magnification 


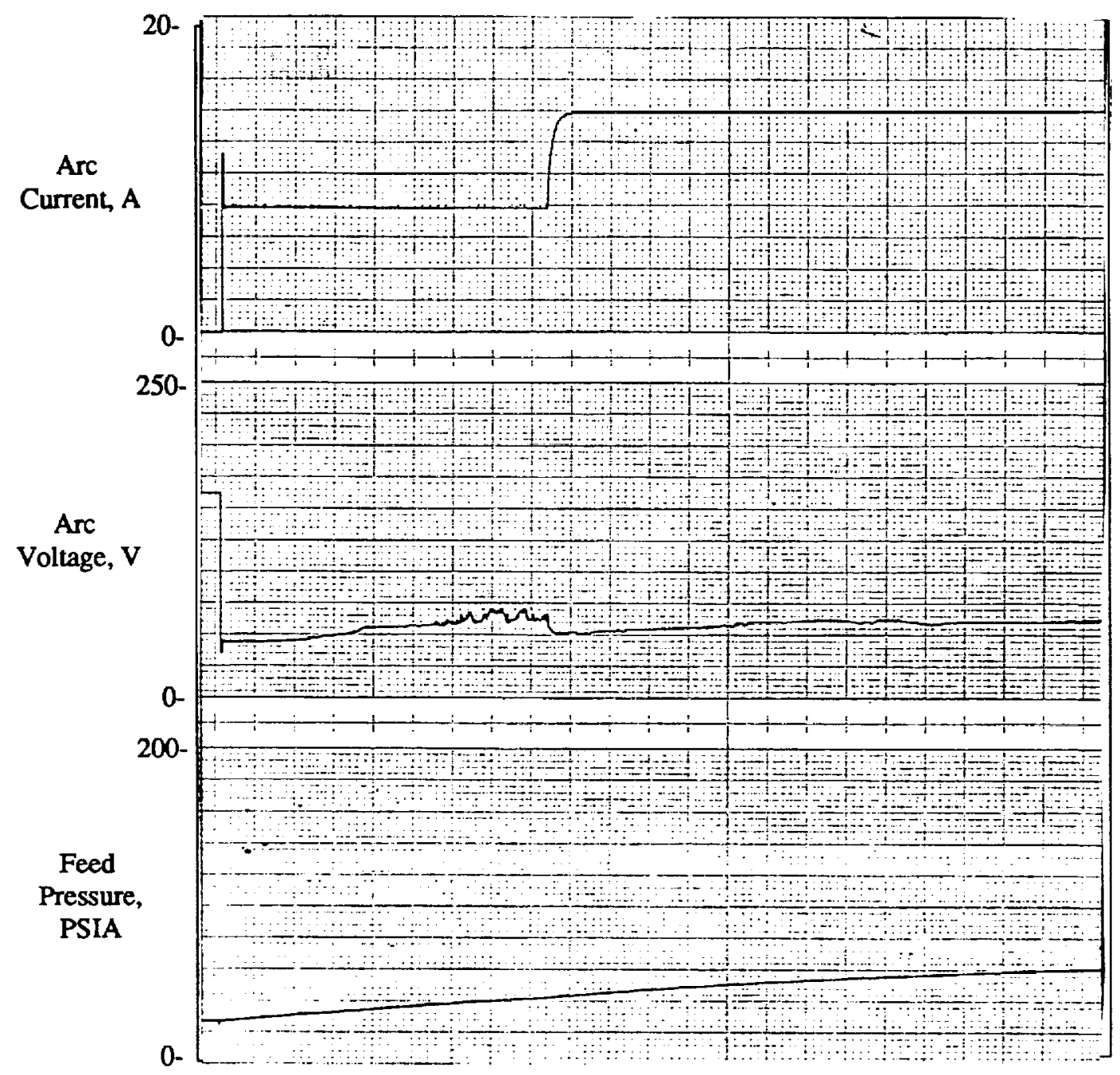

Time, 1 second/division

Figure 23. Arc current, voltage and feed pressure for cycle $401,30 \mathrm{mg} / \mathrm{s}$ flow 


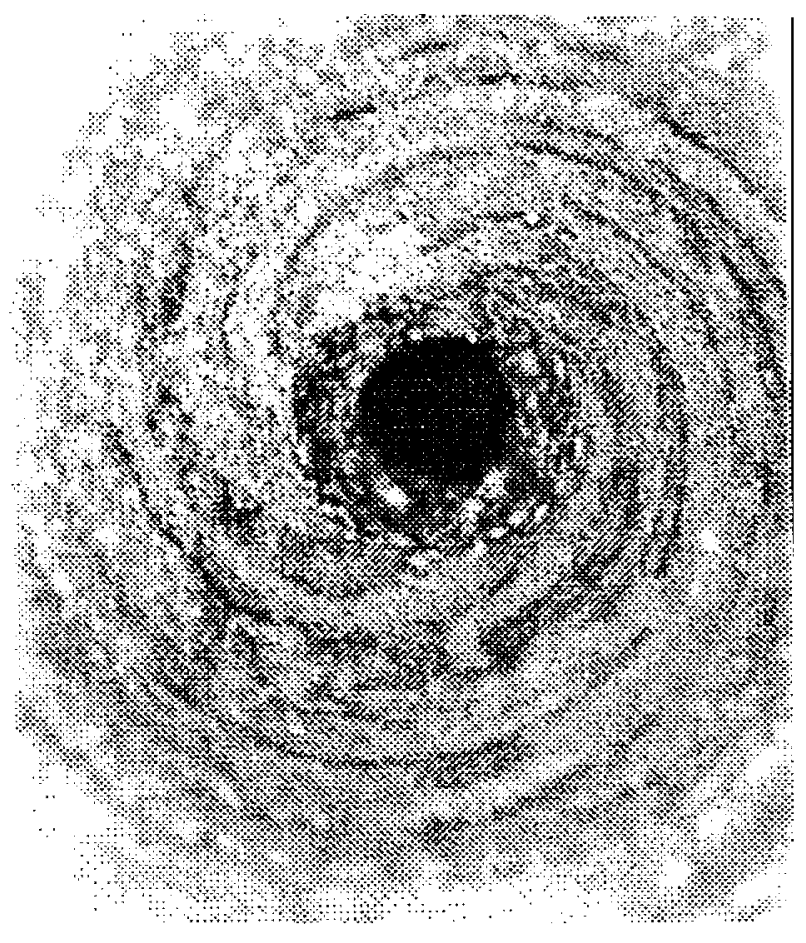

a.) convergent section.

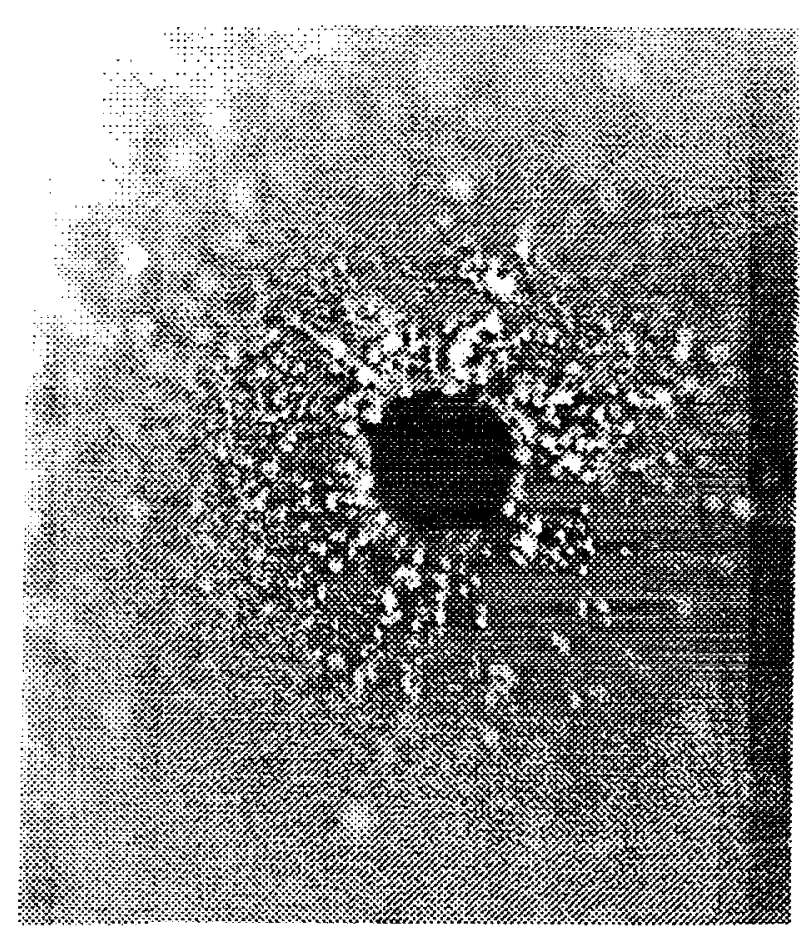

b.) divergent section

Figure 24. Post-test micrographs of the arcjet anode after 500 cycles. $35 \mathrm{X}$ magnification.

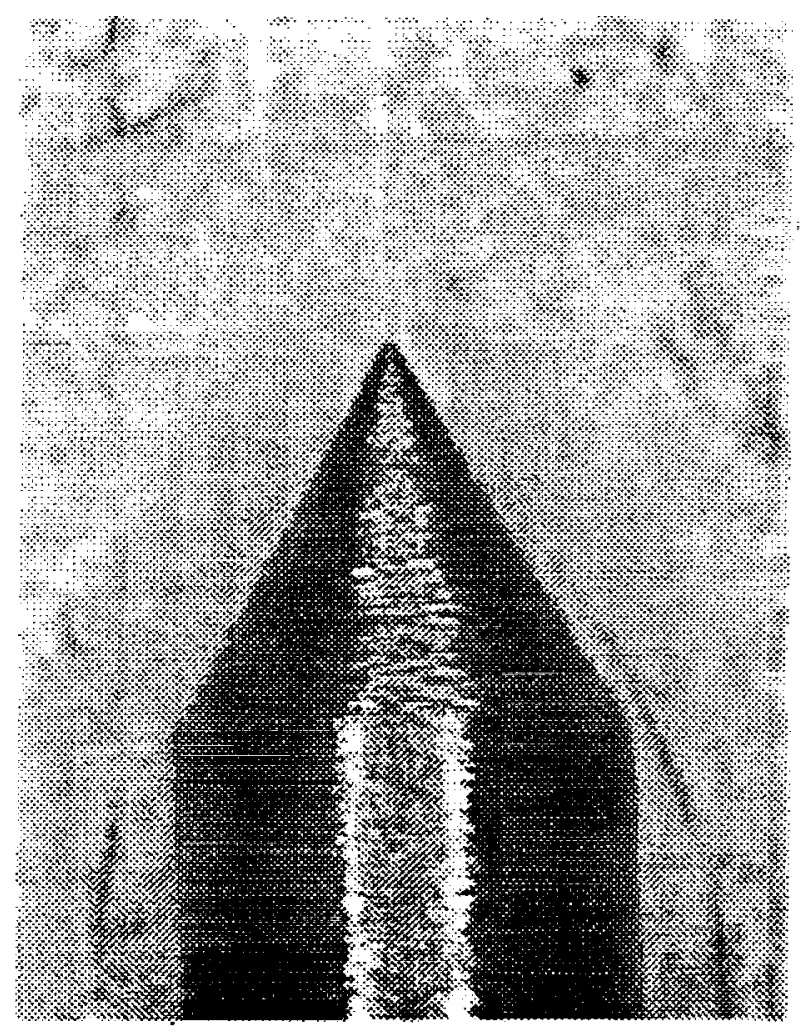

a.) Pre-test

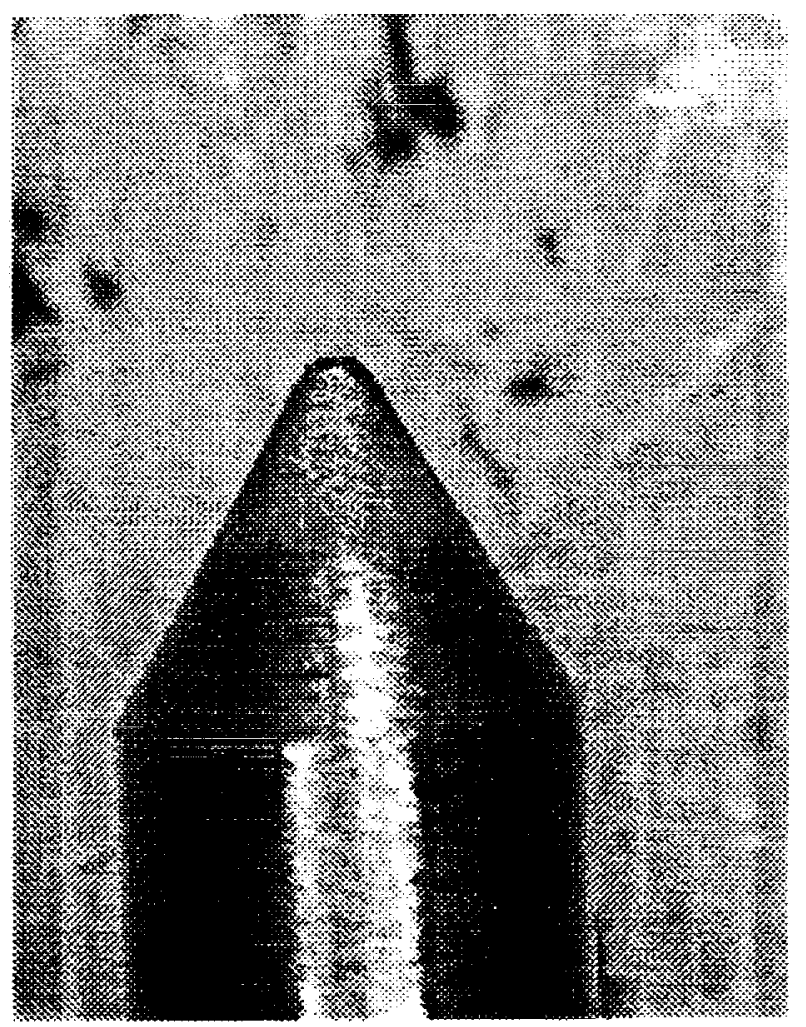

b.) Post-test

Figure 25. Pre- and post-test micrographs of cathode "E," cycles 401-500, 15X magnification 
Public reporting burden for this collection of information is estimated 10 average 1 houf per response, including the time for reviewing instructions, searching existing data sources, Public reporting burden for this colection or intoristion of gathering and maintaining the data needed, and completing ans revin. Washington Headquarters Services, Directorate for Intormation Operations and Reports, 1215 JeHlerson collection of information, including suggestions 2202-4302, and to the Office of Management and Budget, Paperwork Reduction Project (0704-0188), Washington, DC 20503.

Davis Highway, Sutte 1204, Anggton,

\begin{tabular}{|l|c|c|} 
1. AGENCY USE ONLY (Leave blank) & $\begin{array}{c}\text { 2. REPORT DATE } \\
\text { June } 1993\end{array}$ & $\begin{array}{r}\text { 3. REPORT TYPE AND DATES COVERED } \\
\text { Technical Memorandum }\end{array}$
\end{tabular}

\section{TITLE AND SUBTITLE}

A Soft-Start Circuit for Arcjet Ignition

6. AUTHOR(S)

John Hamley and John M. Sankovic

\section{FUNDING NUMBERS}

WU-506-42-31

\section{PERFORMING ORGANIZATION NAME(S) AND ADDRESS(ES)}

National Aeronautics and Space Administration

Lewis Research Center

Cleveland, Ohio 44135-3191
8. PERFORMING ORgANIZATION REPORT NUMBER

E-8025
9. SPONSORINGMONITORING AGENCY NAME(S) AND ADDRESS(ES)

National Aeronautics and Space Administration

Washington, D.C. 20546-0001
10. SPONSORINGMONITORING AGENCY REPORT NUMBER

NASA TM-106287

AIAA-93-2396

11. SUPPLEMENTARY NOTES

Prepared for the 29th AIAA Joint Propulsion Conference and Exhibit, cosponsored by AIAA, SAE, ASME and ASEE, Monterey, California. Responsible person, John Hamely, (216) 977-7430.

12a. DISTRIBUTIONAVAILABILTTY STATEMENT

12b. DISTRIBUTION CODE

Unclassified - Unlimited

Subject Category 30

13. ABSTAACT (Maximum 200 words)

The reduced propellant flow rates associated with high performance arcjets have placed new emphasis on electrode erosion, especially at startup. A soft-start current profile was defined which limited current overshoot during the initial 30 to $50 \mathrm{~ms}$ of operation, and maintained significantly lower than the nominal arc current for the first eight seconds of operation. A $2-5 \mathrm{~kW}$ arcjet PPU was modified to provide this current profile, and a 500 cycle test using simulated fully decomposed hydrazine was conducted to determine the electrode erosion during startup. Electrode geometry and mass flow rates were selected based on requirements for a 600 second specific impulse mission average arcjet system. The flow rate was varied throughout the test to simulate the blow down of a flight propellant system. Electrode damage was negligible at flow rates above $33 \mathrm{mg} / \mathrm{s}$, and minor chamfering of the constrictor occurred at flow rates of 33 to $30 \mathrm{mg} / \mathrm{s}$, corresponding to flow rates expected in the last $40 \%$ of the mission. Constrictor diameter remained unchanged and the thruster remained operable at the completion of the test. The soft-start current profile significantly reduced electrode damage when compared to state of the art starting techniques.

14. SUBJECT TERMS

Arcjet; Electric propulsion; Power processing

17. SECURTYY CLASSIFICATION OF REPORT

Unclassified
18. SECURTY CLASSIFICATION OF THIS PAGE Unclassified
19. SECURITY CLASSIFICATION OF ABSTRACT Unclassified 